$16^{\text {th }}$ International Conference on

AEROSPACE SCIENCES \& AVIATION TECHNOLOGY,

$\boldsymbol{A S A T}$ - 16 - May 26 - 28, 2015, E-Mail: asat@mtc.edu.eg

Military Technical College, Kobry Elkobbah, Cairo, Egypt

Tel : +(202) 24025292 - 24036138, Fax: +(202) 22621908

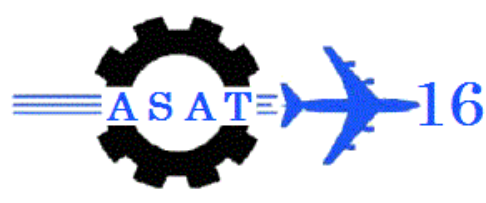

\title{
The Optimization of Base Bleed Grain Parameters for Maximum Ballistic Performance
}

\author{
H.A. Abou-Elela*, Ossama $R^{*}$, A.Z. Ibrahim*, O.K. Mahmoud* and O.E. Abdel-Hamid* \\ * Egyptian Armed Forces
}

\begin{abstract}
Solid propellant Base bleed unit is one of the effective methods to increase the range of artillery projectiles. As far as we search, no published study focuses on the optimal dimensions of the base bleed grain. However, few studies focus on the effect of base bleed grain parameters on its ballistic performance in which each parameter was studied separately. The present optimization study is performed on base bleed grain which performed as longitudinally slotted tubular cylinder. Different case studies have been introduced according to the number of design variables which are: grain outer, inner radius, length, burn rate, base bleed grain unit orifice diameter. Moreover, the study is extended to demonstrate the effect of these parameters on the innovative multi-burn rate base bleed grain. In this new idea, the grain is splitted into two horizontal parts one with higher burn rate than the other part. The idea is to have a grain that provides high mass flow rate in the first seconds of projectile flight, while keeping long bleeding time.

The optimization constrains are the upper and lower limits of each design variable. An analytical model has been developed in $\mathrm{C}++$ environment to accurately evaluate the range of the projectile. This model is then utilized in combination with design of experiment (DOE) and the response surface method (RSM) to develop a smooth response function which can be effectively used in the design optimization formulation as the objective function. The objective of the optimization is to find the design variables which contribute the maximum range.
\end{abstract}


The results show the importance of applying optimization and provided the optimized values of the studied parameters at each case. Also it shows that the application of the new idea of multi-burn rate base bleed increases the range in all cases with percentage up to $12 \%$ with respect to the range increase for the original base bleed grain.

\section{KEY WORDS}

Aerodynamics, base bleed, injection parameter, Burn rate, Optimization, ANSYS, RSM.

\section{Introduction}

Long range is the significant requirement for the developers of new ammunition. Base drag reduction is one of the main concerns to increase the range since it represents more than $50 \%$ of the total drag affecting the projectile at transonic and supersonic speeds [1]. Base bleeding is an effective means to cope base drag via injecting hot burnt gases behind the projectile base. These gases raise the wake region pressure causing base drag reduction.

The effect of base bleeding is characterized by dimensionless injection parameter "I" [2-5]. Experimental work done by (Davenas) [6] showed that the optimum injection parameter, $\mathrm{I}_{\mathrm{op}}$ for base bleed projectile is approximately 0.005 and is calculated according to the following equation $[6,7]$ :

$$
\mathrm{I}=\frac{\dot{\mathrm{m}}_{\mathrm{N}}}{\dot{\mathrm{m}}_{\infty}}
$$

where $\dot{\mathrm{m}}_{\mathrm{N}}$ is the mass flow rate of burnt gases through the base bleed nozzle and $\dot{\mathrm{m}}_{\infty}$ is the upstream mass flow rate of air past the projectile base which can be determined using the following equation [7]:

$$
\dot{\mathrm{m}}_{\infty}=\rho_{\infty} \mathrm{V}_{\infty} \mathrm{A}_{\mathrm{b}},
$$

where $\rho_{\infty}, V_{\infty}$ are the free stream density and velocity, respectively, $A_{b}$ is the area of the boattail base. The mass flow rate $\left(\dot{\mathrm{m}}_{\mathrm{N}}\right)$ is a function of the burning rate of base bleed grain composition and the exposed instantaneous grain surface $\left(\mathrm{A}_{\mathrm{bb}}\right)$.

$$
\dot{\mathrm{m}}_{\mathrm{N}}=\mathrm{U} \mathrm{A}_{\mathrm{bb}} \rho_{\mathrm{bb}},
$$

where $\rho_{\mathrm{bb}}$ and $\mathrm{U}$ are the density and burning rate of the base bleed grain composition, respectively. The grain burning rate can be calculated according to the following equation [7, 8]: 


$$
\mathrm{U}=\mathrm{k} \mathrm{U}_{0} \mathrm{P}_{\mathrm{ch}}^{\alpha}
$$

where $\mathrm{k}$ is the spin rate factor, $\mathrm{U}_{\mathrm{o}}$ is the grain burning rate at atmospheric pressure, $\mathrm{P}_{\mathrm{ch}}$ is the pressure of the base bleed unit chamber and $\alpha$ is the pressure exponent.

Based on the value of mass flow rate of the bleeded gases [5] as shown in Figure (1), there are three regimes of base flow according to the values of injection parameter with respect to the optimum value of it. As the injection parameter increases up to optimum value, the strength of Primary Recirculating Region (PRR) which lies behind the projectile base decreases and the recompression shock is weakened and consequently increases base pressure reaching the maximum value at optimum injection parameter. If the injection parameter exceeds its optimum value, the projectile base pressure decreases until the injected gases have enough momentum to penetrate through the primary recirculation region then the pressure may decrease to a value less than its counterpart without base bleed unit as demonstrated in the experimental work discussed in Ref. 3 and the analytical work in Ref 9.

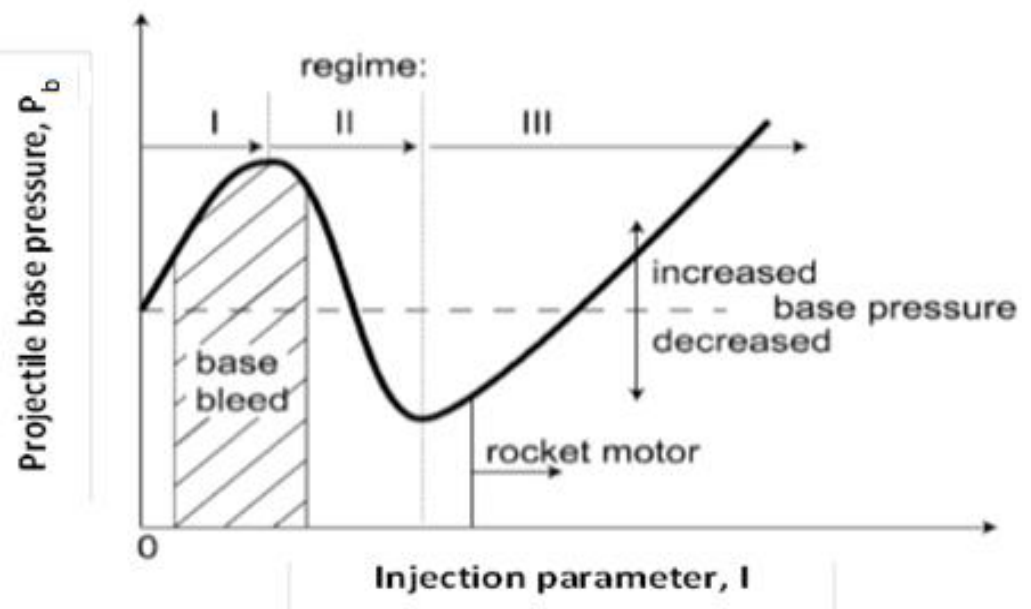

Fig.1 Base pressure versus injected mass flow rate [5]

S. Jaramaz et. al [7] introduced mathematical model that calculates the ballistic performance of base bleed grain. They used it to study the effect of some of the grain parameters on range such as number of segments, burning rate, inner diameter, grain length and base bleed unit orifice. The study was performed in case of 3 and 6 segment grain. They outlined that both the grain length and burn rate have the most important parameters. However they performed the study for each parameter individually without subjecting the results to optimization technique and they excluded grain outer diameter. Also they did not introduce explanations for these outcomes. 
H. Ali et. al. [9] used a validated mathematical model [8] that has been established based on the model introduced by S. Jaramaz et. al [7] to study the effect of different parameters of projectile $155 \mathrm{~mm} \mathrm{K307}$ with base bleed. The base bleed grain is slotted tubular in shape with 2 slots. They included the above mentioned base bleed grain parameters besides the study of the effect of grain outer diameter. They redressed the shortage S. Jaramaz et. al [7] by introducing an explanation for each outcome in conjunction with the time history change of different burnt area of base bleed grain (cylindrical - slots - total), injection parameter and the ballistic parameters of the projectile during base bleed burning. The deeper understand of the results lead to introduce two new techniques to control mass flow rate that ensure the generation of optimum injection parameter; deformable exit diameter, dual-burn base bleed grain. However the results, the study suffered like the previous by not including optimization of the different parameters.
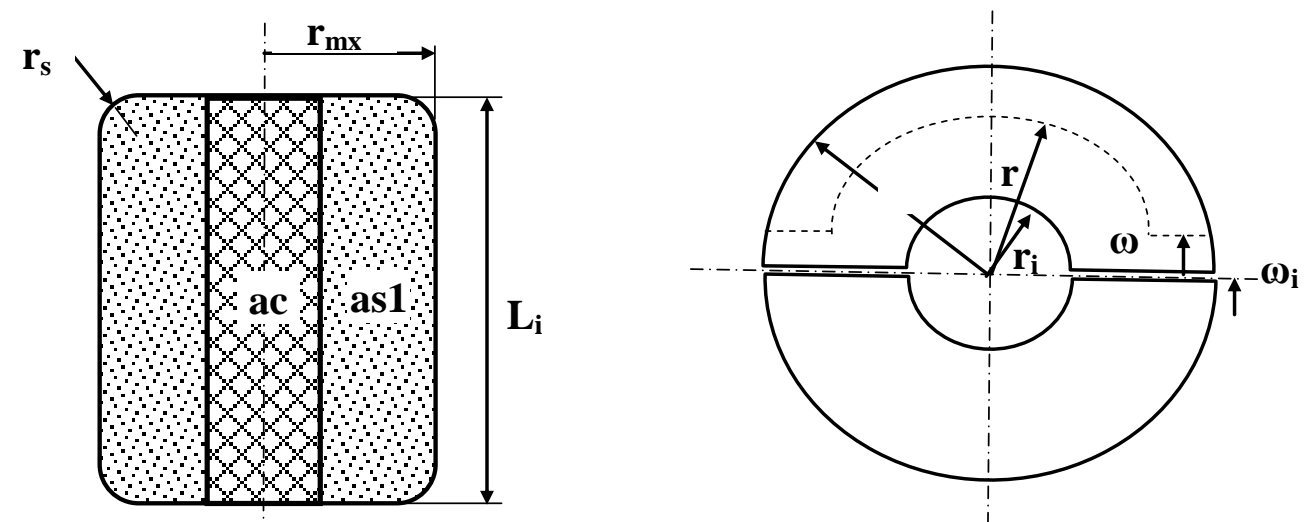

Fig. 2. Base bleed grain different surfaces [9].

Design optimization based on finite element model or computational fluid dynamics is computationally very expensive and may not render accurate optimum results due to the noisy nature of the finite element response. Here, design of experiment (DOE) and the response surface method (RSM) have been utilized to develop a smooth response function (Range of the Shell). DOE has been used to find the best possible combinations of the assigned design variables which cover all the design space. Then using the finite element model, the maximum range has been calculated for each combination to complete the DOE matrix. Later, the Response Surface Method (RSM) has been used to illustrate response surface with the different design variables using a fully quadratic polynomial equation. Finally, the developed objective function has been minimized using first Genetic Algorithm to find the near global optimum solution.

The present study is applied to a base bleed projectile model K307 launched with muzzle velocity $910 \mathrm{~m} / \mathrm{s}$ at angle of fire $51.2^{\circ}$ which corresponds to the maximum range. Base bleed 
grain consists of two identical solid propellant grains as shown in Fig. 2 introduced by H. Ali et. al. [8]. This configuration introduces burnt area of an inner cylinder and four flat slots surfaces. An optimization technique will be used to study the effect of different parameters of the grain including outer radius, $\mathbf{R}_{\mathbf{m a x}}$, inner radius, $\mathbf{R}_{\mathbf{i n}}$, grain length, $\mathbf{L}$, base bleed unit exit diameter, $\mathbf{D}_{\text {exit, }}$ burn rate, $\mathbf{B} \mathbf{R}_{\mathbf{1}}$, and number of slots $\mathbf{N}_{\mathbf{s}}$.

For the new multi-burn rates grain, two parameters will be added; the higher burn rate, $\mathbf{B R}_{\mathbf{2}}$ and grain length ratio $\mathbf{L} \%$ which describes the length of the part with the higher burn rate with respect to grain length. The threshold of the optimization is to achieve maximum range that will be calculated via the already validated $\mathrm{C}++$ model [8]. Different cases of parameters combination will be studied and the outputs will be represented.

\section{Base bleed design variables}

In this study, a semi-analytical model compiled with $\mathrm{C}++[8]$ is fed by the values of base bleed grain variables. The number of variables changes according to each studying case. For each variable, its value changes within a suggested range. Table 1 shows the different cases and the range of each variable. The output of the model which is maximum range will be fed into optimizer mechanism.

The $\mathrm{C}++$ model consists of different subroutines such as; 1) A $2 \mathrm{~d}$ point mass trajectory in which the inputs are the total drag coefficient at different Mach numbers and the corresponding base drag coefficients. CFD was used to split base drag from the total drag. 2) Base bleed grain instantaneous burnt surface area. The surface area is splitted into cylindrical and flat slots areas. The burnet area is consumed according to the burn rate see eq. (3). 3) Base drag reduction subroutine; which calculates the drag reduction during base bleed burn time as function of injection parameter, as shown in Ref.[8]

The validation of the model was performed by comparison of the predicted maximum range, drag coefficient versus Mach number and projectile altitude time history with the experimental data of the projectile $155 \mathrm{~mm} \mathrm{~K} 307$ with base bleed with muzzle velocity $=910$ $\mathrm{m} / \mathrm{s}$ and angle of fire 51.5 degree that corresponds to maximum range.

The results of the model [9] and refs. [11, 12] revel the conditions of getting the maximum range. These conditions are: 1) the base bleed grain should generate injection parameter equal or close to the optimum value $(I=0.005)$ on the trajectory especially at the first 10 seconds of projectile flight with high supersonic velocity. Consequently, the drag reduction is a maximum. Generally, in the first seconds injection parameter is smaller than optimum value 
under the effect of the high values of the free stream conditions as shown in equ. (2) The burn time of base bleed grain should be equal to half or more of the flight time of the projectile.

Different techniques were implemented to control mass flow rate to achieve these conditions such as the change of burn rate, change the base bleed grain configuration and increase the number of slots. The increase of number of slots leads to increase in the burnt area and consequently generates higher injection parameter in the required zone.

In the new introduced technique, the multi-burn rates grain consists of two horizontal parts, the first is manufactured with original burn rate, BR1 which varies from 0.9 up to $1.3 \mathrm{~mm} / \mathrm{s}$. the second part is manufactured with higher burn rate, BR2 that varies from 1.7 up to 2.5 $\mathrm{mm} / \mathrm{s}$ and its length is determined by grain length ratio, $\mathrm{L} \%$. This ratio varies from 0.1 up to 0.5 with respect to the total length of the grain length, L. The burn rate of BR2 provides higher mass flow rate which is required in the first 10 seconds while the BR1 ensures long burn time up to half of the projectile time of flight.

\section{Case studies for the original base bleed grain}

Different cases were studied; the first case is to study the effect of the change of Ns while keeping the other parameters constant and equal to the parameters of the original grain of the projectile K307. In the presiding cases the variable studied parameters are applied gradually up to case \#4 in which it includes all the parameters; outer grain radius, inner radius, exit diameter, burn rate,. The studies were performed in case of different numbers of slots varies from 2 up to 4 . Table 1 shows the cases, the studied variables and the range of each case.

It has been shown in Table 1 that the design variables ranges from (1) variable in case \#2 up to (5) in the last case. 
Table 1. Studied cases of the original base bleed grain, upper and lower constrains of each design variable

\begin{tabular}{|c|c|c|c|c|c|c|}
\hline \multirow{3}{*}{$\begin{array}{l}\text { Optimization Case } \\
\text { study designation }\end{array}$} & \multicolumn{5}{|c|}{ Base bleed studying variables upper and lower limit } & \multirow{2}{*}{$\begin{array}{l}\text { Number } \\
\text { of slots }\end{array}$} \\
\hline & $\begin{array}{l}\text { Outer } \\
\text { radius }\end{array}$ & $\begin{array}{l}\text { Inner } \\
\text { radius }\end{array}$ & Length & $\begin{array}{c}\text { Exit } \\
\text { diameter }\end{array}$ & $\begin{array}{l}\text { Burn } \\
\text { rate }\end{array}$ & \\
\hline & $\begin{array}{l}\mathrm{R}_{\max } \\
{[\mathrm{mm}]}\end{array}$ & $\begin{array}{c}\mathrm{R}_{\mathrm{in}} \\
{[\mathrm{mm}]}\end{array}$ & $\begin{array}{c}\mathrm{L}_{\mathrm{i}} \\
{[\mathrm{mm}]}\end{array}$ & $\begin{array}{l}\mathrm{D}_{\text {exit }}, \\
{[\mathrm{mm}]}\end{array}$ & $\begin{array}{c}\mathrm{BR} 1, \\
{[\mathrm{~mm} / \mathrm{s}]}\end{array}$ & $\mathrm{N}_{\mathrm{s}}$ \\
\hline Case \# 1, PBB 1 & 60 & 20 & 94 & 44 & 1.1 & \multirow{4}{*}{$2-3-4$} \\
\hline Case \# 2, PBB 2 & 60 & 20 & 94 & 44 & $0.9-1.5$ & \\
\hline Case \# 3, PBB 3 & 60 & $18-27$ & 94 & $40-56$ & $0.9-1.3$ & \\
\hline Case \# 4, PBB 4 & $40-70$ & $18-27$ & $75-135$ & $40-56$ & $0.9-1.3$ & \\
\hline
\end{tabular}

\section{Case studies for the multi-burn rates base bleed grain}

In case of multi-burn rates base bleed grain, the previously studied cases are also studied including the effect of $\mathrm{L} \%$ and $\mathrm{BR}_{2}$. In the presiding cases the variable studied parameters are applied gradually while keeping the other parameters constant and equal to the parameters of the original grain of the projectile K307 up to case \#4 in which it includes all the parameters. The studies were performed in case of different numbers of slots varies from 2 up to 4. Table 2 shows the cases, the studied variables and the range of each one.

Table 2. Optimization cases of the multi-burn base bleed grain, upper and lower constrains of each design variable

\begin{tabular}{|c|c|c|c|c|c|c|c|c|}
\hline \multirow{4}{*}{$\begin{array}{l}\text { Case study } \\
\text { designation }\end{array}$} & \multicolumn{7}{|c|}{ Base bleed studying variables upper and lower limit } & \multirow{3}{*}{$\begin{array}{l}\text { Number } \\
\text { of slots }\end{array}$} \\
\hline & \multicolumn{5}{|c|}{ Original variables } & \multicolumn{2}{|c|}{ New variables } & \\
\hline & $\begin{array}{l}\text { Outer } \\
\text { radius }\end{array}$ & $\begin{array}{l}\text { Inner } \\
\text { radius }\end{array}$ & Length & $\begin{array}{c}\text { Exit } \\
\text { diamete } \\
\text { r }\end{array}$ & $\begin{array}{l}\text { Burn } \\
\text { rate }\end{array}$ & $\begin{array}{l}\text { Length } \\
\text { ratio }\end{array}$ & $\begin{array}{l}\text { Burn } \\
\text { rate }\end{array}$ & \\
\hline & $\begin{array}{l}\mathrm{R}_{\max }, \\
{[\mathrm{mm}]}\end{array}$ & $\begin{array}{l}\mathrm{R}_{\mathrm{in}}, \\
{[\mathrm{mm}]}\end{array}$ & $\begin{array}{c}\mathrm{L}, \\
{[\mathrm{mm}]}\end{array}$ & $\begin{array}{l}D_{\text {exit }}, \\
{[\mathrm{mm}]}\end{array}$ & $\begin{array}{c}\mathrm{BR} 1, \\
{[\mathrm{~mm} / \mathrm{s}} \\
]\end{array}$ & $\mathrm{L} \%$ & $\begin{array}{l}\mathrm{BR} 2, \\
{[\mathrm{~mm} / \mathrm{s}]}\end{array}$ & $\mathrm{N}_{\mathrm{s}}$ \\
\hline case \# $1, \mathrm{MBB} 1$ & 60 & 20 & 94 & 44 & 1.1 & \multirow{4}{*}{$\begin{array}{c}0.1- \\
0.5\end{array}$} & \multirow{4}{*}{$1.7-2.5$} & \multirow{4}{*}{$2-3-4$} \\
\hline Case \# 2, MBB 2 & 60 & 20 & 94 & 44 & $\begin{array}{l}0.9- \\
1.3\end{array}$ & & & \\
\hline $\begin{array}{c}\text { Case \# } 3, \mathrm{MBB} \\
3 \\
\end{array}$ & 60 & $18-27$ & 94 & $40-56$ & $\begin{array}{c}0.9- \\
1.3\end{array}$ & & & \\
\hline $\begin{array}{c}\text { Case \# } 4, \text { MBB } \\
4\end{array}$ & $\begin{array}{l}40- \\
70\end{array}$ & $18-27$ & $\begin{array}{l}75- \\
135\end{array}$ & $40-56$ & $\begin{array}{c}0.9- \\
1.3\end{array}$ & & & \\
\hline
\end{tabular}


It has been shown in Table 2 that the design variables are the first case is (2) and in the last case are (7).

\section{Design Optimization Formulation}

In the optimization problem, design requirements or objectives are identified as maximization of range of the projectile K307. The total design variables have been considered to be $R_{\max }$, $\mathrm{R}_{\mathrm{in}}, \mathrm{L}, \mathrm{D}_{\text {exit }}, \mathrm{BR} 1, \mathrm{~L} \%$ and BR2. Also constraints in the form of upper and lower limits have introduced as shown in tables 1,2 .

\section{Derivation of Objective Functions}

The C++ model [8] was used to evaluate accurately the range of the shell and consequently the established objective functions for each combination of the different design variable. As mentioned before, the established objective is maximization of the range of the shell within the boundaries of the prementioned design variables. To formulate the design optimization problems, one may combine the $\mathrm{C}++$ model with optimization algorithms, however this would be computationally very expensive due to the iterative nature of the optimization problem in which at each iteration the objective functions may be evaluated (running the $\mathrm{C}++$ model) several times. Besides, the optimal results may not be accurate due to the possible noisy nature of the output response and also difficulty to establish the derivative of the objective functions required for higher order optimization algorithms.

Considering the above, in this study design of experiment (DOE) and response surface method (RSM) combined with the $\mathrm{C}++$ model are effectively used to derive desired objective functions which will be directly related to the design variables for each combination. DOE has been used to identify the best location of design variables (design points) to accurately map the given design space for each combination of different design variables. Once the DOE matrix has been established, the maximum values of the response (Range of the shell) have been calculated using the $\mathrm{C}++$ model for each row (design point) in the DOE matrix. Then, RSM based on fully quadratic response function has been used to relate the variations of range of the shell with respect to different design variables for each combination. Finally, these response functions have been effectively utilized as objective functions in the design optimization problems. In the following, brief discussion regarding DOE and RSM to derive DOE matrices and response surfaces are presented, respectively. 


\section{Design of Experiment matrices}

Design of Experiments, DOE, is a tactic to develop an experimentation strategy that maximizes learning using a minimum of resources. In many applications, the scientist is constrained by resources and time, to investigate the numerous factors that affect these complex processes using trial and error methods. Instead, (DOE) is an influential tool that permits for multiple input factors to be manipulated determining their effect on a desired output (response). By manipulating multiple inputs at the same time, DOE can recognize important interactions that may be missed when experimenting with one factor at a time. All possible combinations can be investigated (full factorial) or only a portion of the possible combinations (fractional factorial) [13].

In this study, central composite design with enhanced template technique has been used which gives $2 *\left(2 * \mathrm{~K}+2^{(\mathrm{k}-\mathrm{f})}\right)$ factorials plus the central point with the total of 29 different combinations where, $\mathrm{k}$ is the number of the design variables and $\mathrm{f}$ is the fractional number which depends on the value of $\mathrm{k} \quad(\mathrm{f}=0.0$ for $\mathrm{k} \leq 5$ and $\mathrm{f}=1$ for $\mathrm{k}=6,7$ ) [13]. Table 3 shows the DOE Matrix for the original base bleed case study \#3, PBB3 after finding the corresponding range of the shell using the code $\mathrm{C}++$. In which, it has (3) variables as described in Table 1.Optimization Techniques.

The developed approximate response surface functions can now be effectively used in the design optimization problems which aim at finding optimum design variables to satisfy the Maximum Range of the shell.

In this work, Genetic Algorithm (GA) [18] has been employed to accurately capture the optimal configurations for each combination. It is important to mention that the GA has been conducted using the ANSYS 14.5 optimization Design Exploration toolbox. 
Table 1. DOE Matrix for the third combination, $\mathrm{PBB} 3$ in case of $\mathrm{Ns}=2$

\begin{tabular}{|c|c|c|c|c|}
\hline DVs & \multirow{2}{*}{$\mathrm{R}_{\mathrm{in}},[\mathrm{mm}]$} & \multirow{2}{*}{$\mathrm{D}_{\text {exit }},[\mathrm{mm}]$} & \multirow{2}{*}{$\mathrm{BR}_{1}, \mathrm{~mm} / \mathrm{s}$} & \multirow{2}{*}{$\begin{array}{l}\text { Range, } \\
\mathrm{X}_{\mathrm{op}}[\mathrm{m}]\end{array}$} \\
\hline Combinations & & & & \\
\hline 1 & 22.5 & 48 & 1.1 & 40462.7 \\
\hline 2 & 18 & 48 & 1.1 & 40179.3 \\
\hline 3 & 20.25 & 48 & 1.1 & 40326 \\
\hline 4 & 27 & 48 & 1.1 & 40581.7 \\
\hline 5 & 24.75 & 48 & 1.1 & 40569.9 \\
\hline 6 & 22.5 & 48 & 0.9 & 39717.6 \\
\hline 7 & 22.5 & 48 & 1 & 40151.3 \\
\hline 8 & 22.5 & 48 & 1.3 & 40731.9 \\
\hline 9 & 22.5 & 48 & 1.2 & 40660.9 \\
\hline 10 & 22.5 & 40 & 1.1 & 40080.6 \\
\hline 11 & 22.5 & 44 & 1.1 & 40436.4 \\
\hline 12 & 22.5 & 56 & 1.1 & 40459.3 \\
\hline 13 & 22.5 & 52 & 1.1 & 40462.5 \\
\hline 14 & 18 & 40 & 0.9 & 39438.7 \\
\hline 15 & 20.25 & 44 & 1 & 40014.3 \\
\hline 16 & 27 & 40 & 0.9 & 40084.7 \\
\hline 17 & 24.75 & 44 & 1 & 40302.3 \\
\hline 18 & 18 & 40 & 1.3 & 39493 \\
\hline 19 & 20.25 & 44 & 1.2 & 40489 \\
\hline 20 & 27 & 40 & 1.3 & 39122.5 \\
\hline 21 & 24.75 & 44 & 1.2 & 40579.6 \\
\hline 22 & 18 & 56 & 0.9 & 39220.6 \\
\hline 23 & 20.25 & 52 & 1 & 39977.6 \\
\hline 24 & 27 & 56 & 0.9 & 39985.4 \\
\hline 25 & 24.75 & 52 & 1 & 40278.3 \\
\hline 26 & 18 & 56 & 1.3 & 40650.5 \\
\hline 27 & 20.25 & 52 & 1.2 & 40575.1 \\
\hline 28 & 27 & 56 & 1.3 & 40553.8 \\
\hline 29 & 24.75 & 52 & 1.2 & 40722.9 \\
\hline
\end{tabular}

\section{RESULTS and DISCUSSIONS}

In the following, the results of optimization technique for each case study mentioned in Tables $(1,2)$ have been introduced. It includes; the optimized design variables with its corresponding predicted maximum range, $\mathrm{X}_{\mathrm{op}}$ for three candidate points. The $\mathrm{C}++$ code [8] will be fed by these values and the output range, $X_{\text {anlt }}$ will be compared with $\mathrm{X}_{\mathrm{op}}$. The relative difference between the two values of range for the same design variables at each candidate point will be calculated as shown in equation (7):

$$
\Delta \mathrm{X}=\frac{\left(\mathrm{X}_{\mathrm{anlt}}-\mathrm{X}_{\mathrm{op}}\right)}{\mathrm{X}_{\mathrm{anlt}}} \%
$$


Eqn. (8) has been used to calculate difference in percentage of range increase between the new idea MBB and the original base bleed projectile P-BB:

$$
\Delta X_{B B \text { gain }}=\left[\frac{\left(X_{\text {ant }}^{M B B}-X_{\text {inrt }}\right)}{\left(X_{\text {anlt }}^{O B B}-X_{\text {inrt }}\right)}-1\right) \%
$$

where, $X_{a n l t}^{M B B}$ and $X_{\text {anlt }}^{O B B}$ are the maximum range when feeding the $\mathrm{C}++$ code with the corresponding candidate points in case of the new multi-burn base bleed, MBB and the original base bleed, PBB, respectively. $X_{\text {inrt }}$ is the analytical predicted range of the projectile with inert base bleed [8].

Also, the results will include samples of optimization outputs such as local sensitivity and response surface for selected cases and outputs from $\mathrm{C}++$ code. The cases of the original

\section{base bleed grain, PBB}

Table 4 shows the optimized design variables at each candidate point and the corresponding range $X_{o p}, X_{\text {anlt }}$ and the relative difference in range. In the first case, all the parameters are constant and equal to the values of K307 projectile grain and just showing the change of range with $\mathrm{N}_{\mathrm{s}}$. In the second and third cases, it has been observed that the optimized values of BR1 tend to be close to the upper limit as BR1 is the only source of mass flow rate. however, in the last case the optimized values of BR1 tend to be close to the lower limits because in this case the design variables includes $\mathrm{R}_{\max }$ and $\mathrm{L}$ which can be considered as the main source of mass flow rate. For cases (2, 3 and 4) it appears that the lower value of $R_{\text {in }}$ is optimal value. Meanwhile, higher values of $D_{\text {exit }}$ are required for longer range to allow the high mass flow rate to flow with reasonable injection parameter $[9,12]$. The maximum difference between $X_{o p}$, and $X_{\text {anlt }}$ is found in the case PBB 4 in which the number of design variables is the maximum. 
Table 4. Studied design variables at each candidate point, the corresponding range $X_{\mathrm{op}}, X_{\text {anlt }}$ and the relative difference in range.

\begin{tabular}{|c|c|c|c|c|c|c|c|c|c|c|}
\hline \multirow[b]{2}{*}{ No. } & \multirow[b]{2}{*}{ Configuration } & \multirow{2}{*}{$\begin{array}{c}\text { Number } \\
\text { of slots, } \\
\mathrm{N}_{\mathrm{s}}\end{array}$} & \multicolumn{5}{|c|}{ Optimized Design Variable } & \multicolumn{2}{|c|}{ Predicted Range } & \multirow{2}{*}{$\begin{array}{c}\text { Abs. } \\
\text { Relative } \\
\text { Differ. in } \\
\text { Range[\%] }\end{array}$} \\
\hline & & & $\begin{array}{l}\mathbf{R}_{\max }, \\
{[\mathrm{mm}]}\end{array}$ & $\begin{array}{c}\mathrm{R}_{\mathrm{in}}, \\
{[\mathrm{mm}]}\end{array}$ & $\begin{array}{c}\mathrm{L}, \\
{[\mathrm{mm}]}\end{array}$ & $\begin{array}{l}\mathrm{D}_{\text {exit }}, \\
{[\mathrm{mm}]}\end{array}$ & $\begin{array}{c}\mathrm{BR} 1, \\
{[\mathrm{~mm} / \mathrm{s}]}\end{array}$ & $\begin{array}{l}X_{o p}, \\
{[\mathrm{~m}]}\end{array}$ & $\begin{array}{c}X_{\text {anlt }}, \\
{[\mathrm{m}]}\end{array}$ & \\
\hline \multirow{3}{*}{1} & \multirow{3}{*}{$\begin{array}{c}\text { Case \# } 1 \text {, } \\
\text { PBB } 1\end{array}$} & 2 & - & - & - & - & 1.1 & - & 40516 & - \\
\hline & & 3 & - & - & - & - & 1.1 & - & 41236 & - \\
\hline & & 4 & - & - & - & - & 1.1 & - & 41717 & - \\
\hline \multirow{9}{*}{2} & \multirow{9}{*}{$\begin{array}{c}\text { Case \# 2, } \\
\text { PBB2 }\end{array}$} & \multirow{3}{*}{2} & - & - & - & - & 1.26 & 40702 & 40703 & $0.00 \%$ \\
\hline & & & - & - & - & - & 1.23 & 40693 & 40696 & $0.01 \%$ \\
\hline & & & - & - & - & - & 1.34 & 40665 & 40661 & $0.01 \%$ \\
\hline & & \multirow{3}{*}{3} & - & - & - & - & 1.26 & 41436 & 41440 & $0.01 \%$ \\
\hline & & & - & - & - & - & 1.23 & 41426 & 41434 & $0.02 \%$ \\
\hline & & & - & - & - & - & 1.33 & 41396 & 41389 & $0.02 \%$ \\
\hline & & \multirow{3}{*}{4} & - & - & - & - & 1.23 & 41862 & 41872 & $0.02 \%$ \\
\hline & & & - & - & - & - & 1.20 & 41853 & 41866 & $0.03 \%$ \\
\hline & & & - & - & - & - & 1.30 & 41826 & 41826 & $0.00 \%$ \\
\hline \multirow{9}{*}{3} & \multirow{9}{*}{$\begin{array}{c}\text { Case \# 3, } \\
\text { PBB3 }\end{array}$} & \multirow{3}{*}{2} & - & 18.1 & - & 48.9 & 1.25 & 40846 & 40689 & $0.388 \%$ \\
\hline & & & - & 26.2 & - & 49.6 & 1.23 & 40794 & 40651 & $0.352 \%$ \\
\hline & & & - & 18.2 & - & 53.6 & 1.26 & 40791 & 40728 & $0.154 \%$ \\
\hline & & \multirow{3}{*}{3} & - & 18.1 & - & 56 & 1.30 & 41663 & 41613 & $0.121 \%$ \\
\hline & & & - & 19.3 & - & 54.7 & 1.28 & 41599 & 41561 & $0.093 \%$ \\
\hline & & & - & 18.7 & - & 50.5 & 1.28 & 41571 & 41585 & $0.033 \%$ \\
\hline & & \multirow{3}{*}{4} & - & 18 & - & 53.8 & 1.28 & 42144 & 42100 & $0.105 \%$ \\
\hline & & & - & 18.1 & - & 48.9 & 1.25 & 42126 & 42084 & $0.100 \%$ \\
\hline & & & - & 18.1 & - & 44.2 & 1.28 & 42117 & 42131 & $0.034 \%$ \\
\hline \multirow{9}{*}{4} & \multirow{9}{*}{$\begin{array}{c}\text { Case \# 4, } \\
\text { PBB4 }\end{array}$} & \multirow{3}{*}{2} & 52.7 & 18 & 129.9 & 56 & 0.90 & 42927 & 40466 & $6.08 \%$ \\
\hline & & & 59.9 & 18.1 & 99.33 & 54.1 & 0.92 & 41935 & 39944 & $4.98 \%$ \\
\hline & & & 56.1 & 18.4 & 114.4 & 54.7 & 1.08 & 41777 & 40738 & $2.55 \%$ \\
\hline & & \multirow{3}{*}{3} & 58.3 & 18 & 114.4 & 55.4 & 0.90 & 43324 & 41223 & $5.10 \%$ \\
\hline & & & 63.1 & 18.2 & 115.5 & 48.8 & 0.91 & 42959 & 41714 & $2.98 \%$ \\
\hline & & & 49.9 & 18.1 & 123.6 & 52.5 & 0.94 & 42405 & 40771 & $4.01 \%$ \\
\hline & & \multirow{3}{*}{4} & 63.0 & 18 & 86.23 & 55.1 & 1.30 & 43231 & 42123 & $2.63 \%$ \\
\hline & & & 59.9 & 18.1 & 99.33 & 54.1 & 0.92 & 43040 & 41350 & $4.09 \%$ \\
\hline & & & 63.1 & 18.2 & 115.5 & 48.8 & 0.91 & 42948 & 42437 & $1.20 \%$ \\
\hline
\end{tabular}

To increase the accuracy in the case PBB 4, the upper and the lower limits of the variables have been reduced and then being optimized again. Table 5 shows the new reduced upper and lower limits for the design variables which in such case 
Table 5. Reduced upper and lower limits of the design variables for the case PBB $4 \mathrm{R}$

\begin{tabular}{|c|c|c|c|c|c|c|}
\hline \multirow{3}{*}{$\begin{array}{l}\text { Optimization Case } \\
\text { study designation }\end{array}$} & \multicolumn{5}{|c|}{ Base bleed studying variables upper and lower limit } & \multirow{2}{*}{$\begin{array}{l}\text { Number } \\
\text { of slots }\end{array}$} \\
\hline & $\begin{array}{l}\text { Outer } \\
\text { radius }\end{array}$ & $\begin{array}{c}\text { Inner } \\
\text { radius }\end{array}$ & Length & $\begin{array}{c}\text { Exit } \\
\text { diameter }\end{array}$ & $\begin{array}{c}\text { Burn } \\
\text { rate }\end{array}$ & \\
\hline & $\begin{array}{l}\mathrm{R}_{\max }, \\
{[\mathrm{mm}]}\end{array}$ & $\begin{array}{c}\mathrm{R}_{\mathrm{in}}, \\
{[\mathrm{mm}]}\end{array}$ & $\begin{array}{c}\mathrm{L}_{\mathrm{i}}, \\
{[\mathrm{mm}]}\end{array}$ & $\begin{array}{l}D_{\text {exit }}, \\
{[\mathrm{mm}]}\end{array}$ & $\begin{array}{c}\text { BR1, } \\
{[\mathrm{mm} / \mathrm{s}]}\end{array}$ & $\mathrm{N}_{\mathrm{s}}$ \\
\hline Case \# 4, PBB $4 \mathrm{R}$ & $52.5-70$ & $18-27$ & $90-125$ & $40-56$ & $0.9-1.3$ & $2-3-4$ \\
\hline
\end{tabular}

Table 6 shows the results after performing the above mentioned limits. It can be seen that the error have has been reduced significantly and the values of $X_{\text {anlt }}$ has been used in the next comparisons.

Figure 3 shows the comparison between the range of the projectile in case of ordinary base bleed grain, PBB 1 and the range in case of PBB 2 for different values of Ns and the percent of range increase, respectively.

For all values of Ns, the range is longer in case of PBB 2 in which BR1 is the only optimized variable and its value is higher than the original burn rate of the projectile grain (see Table 4).

Table 6. Studied design variables at each candidate point, the corresponding range $X_{o p}, X_{\text {anlt }}$ and the relative difference in range for PBB $4 \mathrm{R}$.

\begin{tabular}{|c|c|c|c|c|c|c|c|c|c|c|}
\hline \multirow[b]{2}{*}{ No. } & \multirow{2}{*}{ Configuration } & \multirow{2}{*}{$\begin{array}{c}\text { Number } \\
\text { of slots, } \\
\mathrm{N}_{\mathrm{s}}\end{array}$} & \multicolumn{5}{|c|}{ Optimized Design Variable } & \multicolumn{2}{|c|}{$\begin{array}{c}\text { Predicted } \\
\text { Range, } X[\mathrm{~m}]\end{array}$} & \multirow{2}{*}{$\begin{array}{c}\text { Abs. } \\
\text { Relative } \\
\text { Differ. } \\
\text { in } \\
\text { Range } \\
{[\%]}\end{array}$} \\
\hline & & & $\begin{array}{l}\mathrm{R}_{\max } \\
{[\mathrm{mm}]}\end{array}$ & $\mathrm{R}_{\mathrm{in}},[\mathrm{mm}]$ & $\begin{array}{c}\mathrm{L}, \\
{[\mathrm{mm}]}\end{array}$ & $\begin{array}{l}\mathrm{D}_{\text {exit }} \\
{[\mathrm{mm}]}\end{array}$ & $\begin{array}{l}\mathrm{BR} 1, \\
{[\mathrm{~mm} / \mathrm{s}]}\end{array}$ & $\begin{array}{l}X_{\mathrm{op}} \\
{[\mathrm{m}]}\end{array}$ & $\begin{array}{l}X_{\text {anlt }}, \\
{[\mathrm{m}]}\end{array}$ & \\
\hline \multirow{9}{*}{1} & \multirow{9}{*}{$\begin{array}{l}\text { Original base } \\
\text { bleed \# } 4 \\
\text { reduced, PBB } \\
4 \mathrm{R}\end{array}$} & \multirow{3}{*}{2} & 58.6 & 18 & 132 & 56 & 0.90 & 42317 & 40855 & 3.58 \\
\hline & & & 63.2 & 20.38 & 127 & 55.5 & 0.91 & 41942 & 41006 & 2.28 \\
\hline & & & 58.3 & 18.05 & 126 & 52.5 & 0.94 & 41831 & 40794 & 2.54 \\
\hline & & \multirow{3}{*}{3} & 58.5 & 18 & 131 & 56 & 0.90 & 43271 & 41756 & 3.63 \\
\hline & & & 63.2 & 20.38 & 127 & 55.5 & 0.91 & 42778 & 41905 & 2.08 \\
\hline & & & 65 & 21.5 & 121 & 56 & 0.94 & 42549 & 41904 & 1.52 \\
\hline & & \multirow{3}{*}{4} & 58.3 & 18 & 131 & 56 & 0.90 & 43802 & 42446 & 3.19 \\
\hline & & & 58.3 & 18.09 & 126 & 52.5 & 0.94 & 43407 & 42430 & $-2.30 \%$ \\
\hline & & & 63.2 & 20.4 & 127 & 55.5 & 0.91 & 43248 & 42494 & $-1.77 \%$ \\
\hline
\end{tabular}

Figure 4 shows the predicted change of injection parameter with burn time in the above mentioned cases. For all values of Ns, Burn time of optimized base bleed grain, PBB 2 is less than the corresponding time of PBB 1. This is related to the higher value of BR1 in case of PBB 2 (see Table 4) where as BR1 in the case PBB 1 is $1.1 \mathrm{~mm} / \mathrm{s}$. Another result of the 
higher BR1 is the higher injection parameter in most of burn time. Despite the decrease in burn time, the high injection parameter in the first seconds of burn time compensates the negative effect of burn time reduction and so the range increases.

Figure 5 shows the change of projectile Mach number versus time of flight for PBB 2 with 2 and 4 slots. It is clear the benefit of the increase of injection parameter in the first seconds and the decrease of it in the remaining burn time which gets the values of injection parameter closer to the optimum value as shown in Fig.4.

Figure 6 shows the response surface of range with BR1 in case of PBB 2 for $\mathrm{N}_{\mathrm{s}}=2,3$ and 4 respectively. Generally, the range increases with the increase of BR1 up to an optimum value and beyond this value the range decreases. The optimum values of BR1 decreases with the increase of $\mathrm{Ns}$ as it can be seen in Table 3. The increase of Ns is considered one of the main mechanisms to increases mass flow rate and consequently the optimized value of BR1 is reduced with the increase of Ns for the same exit diameter, $D_{\text {exit }}$ [9].

Figure 7 shows the response surface of range change with grain $R_{\max }$ for different grain $L$ in the case PBB $4 \mathrm{R}$ for $\mathrm{Ns}=2$ and 4 . The high effect of $\mathrm{R}_{\max }$ change for all values of $\mathrm{L}$ on range is obvious. The trend of range change with $R_{\max }$ in figures (a) and (b) is the same; the range increases with the increase of $R_{\max }$ till an optimum value which depends on the value of $\mathrm{L}$ and Ns. The optimum $\mathrm{R}_{\max }$ is higher in case of low value of $L$. also for the same $L$, the optimum value of $R_{\max }$ is higher in case Ns $=2$ than in case of Ns $=4$.

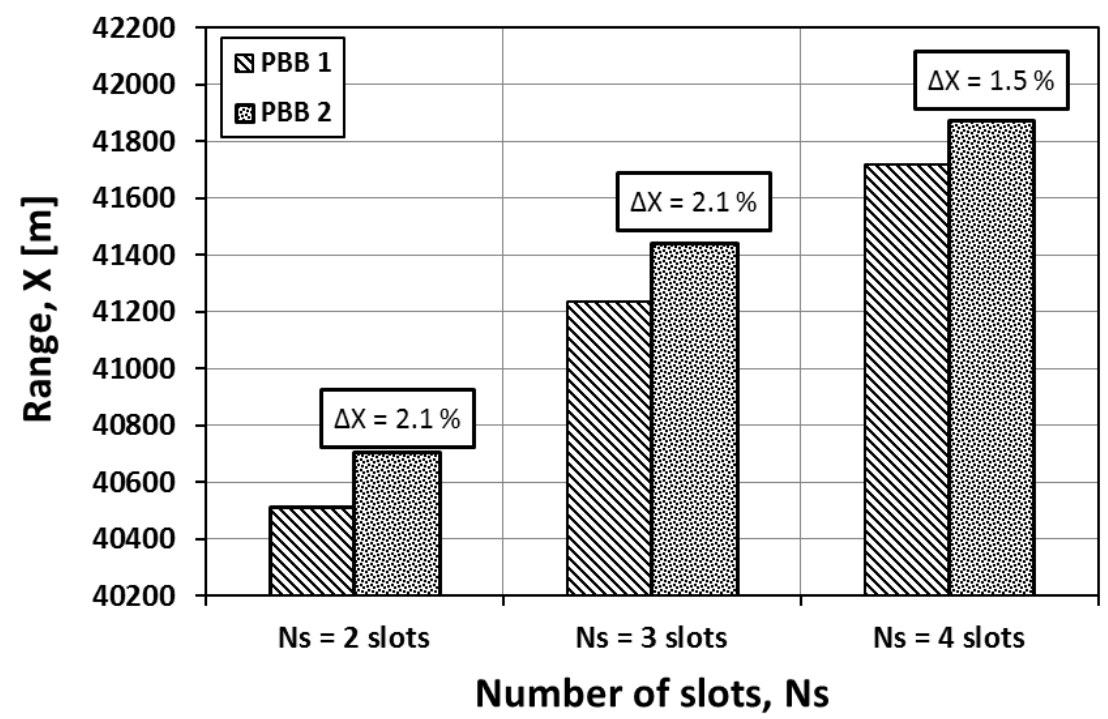

Fig. 3. The predicted range in case PBB 1 compared with the range of the case of PBB 2 for different $\mathrm{N}_{S}$. 


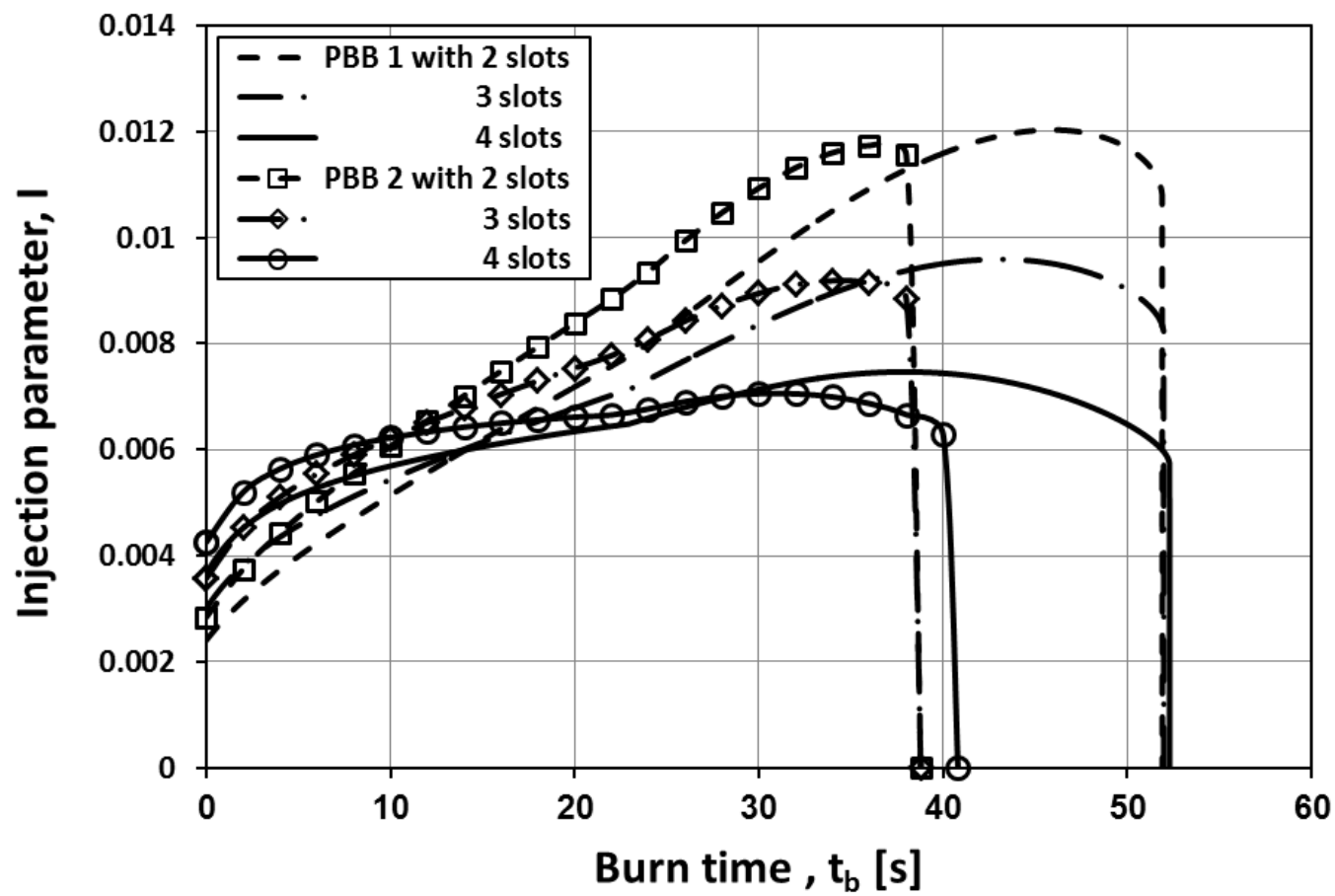

Fig.4. The predicted change of injection parameter with burn time in case of PBB 1 compared with the corresponding injection parameter of the case of PBB 2 for different $\mathrm{N}_{\mathrm{S}}$.

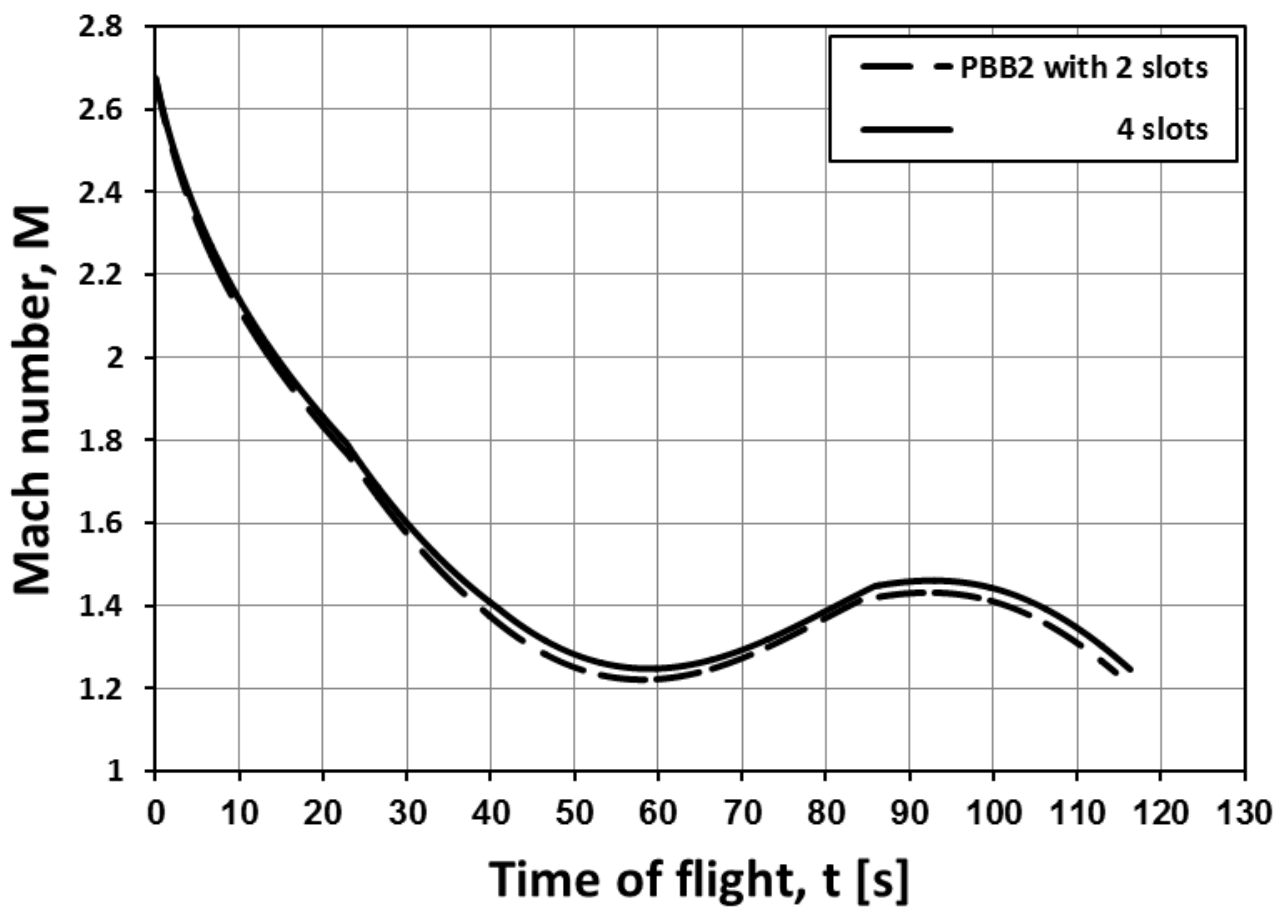

Fig. 5 Change of projectile Mach number versus time of flight for PBB 2 with

$$
\text { Ns }=2 \text { and } 4 .
$$




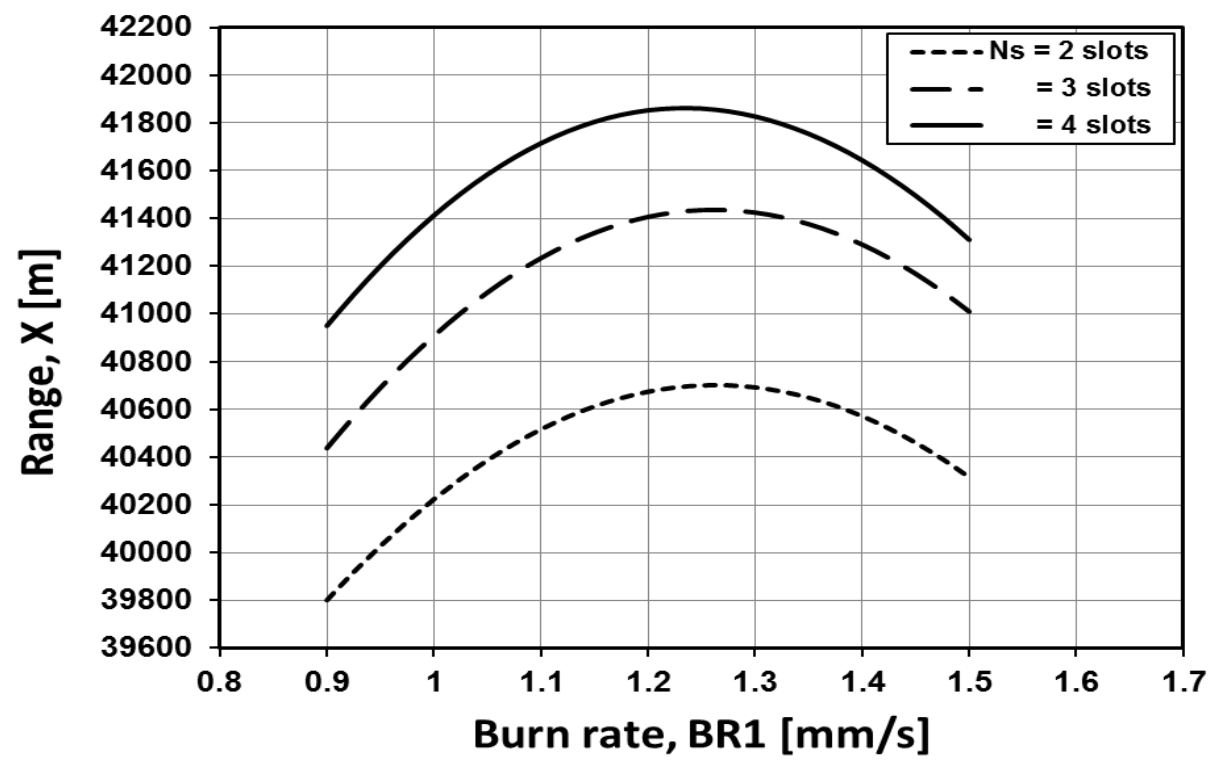

Fig.6 The response surface of range change with BR1 in the case PBB 2 for different $\mathrm{N}_{S}$.

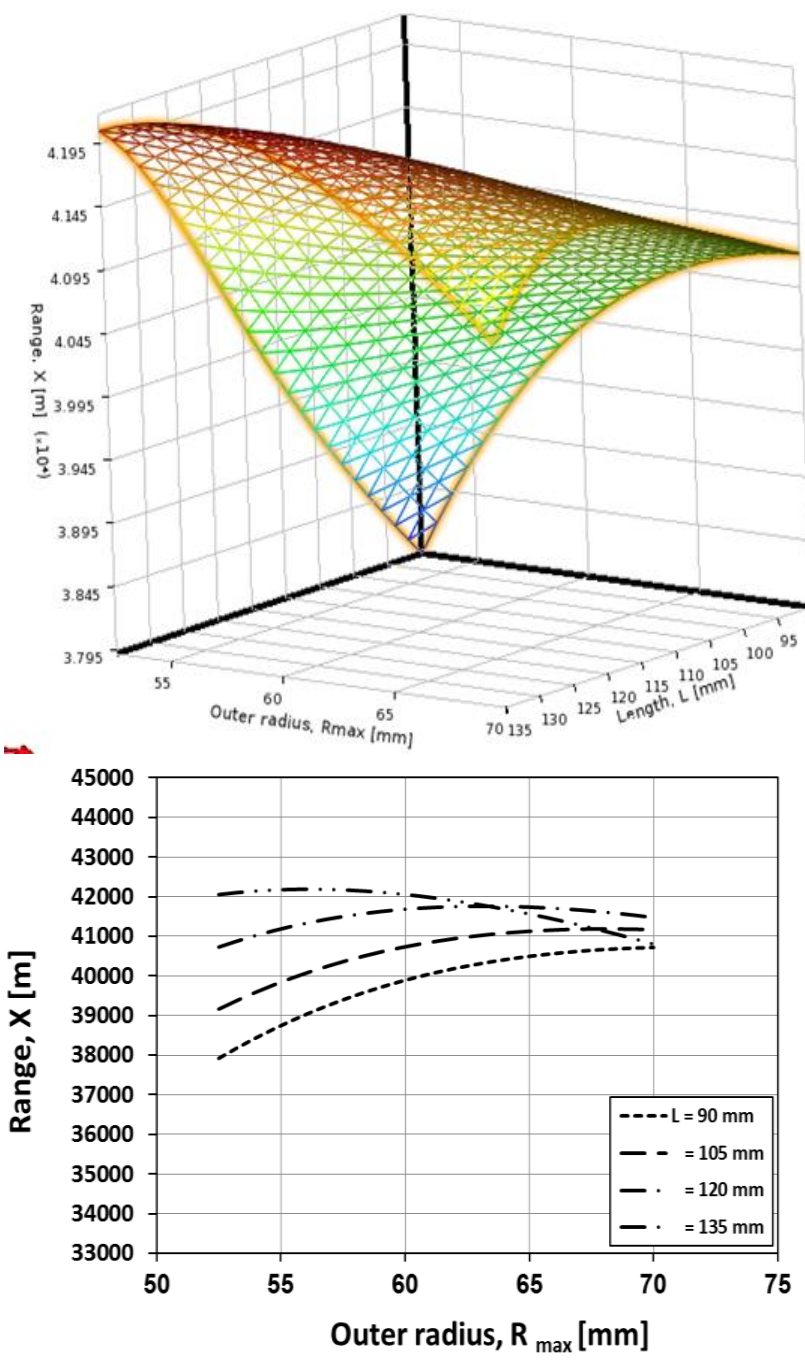

(a)
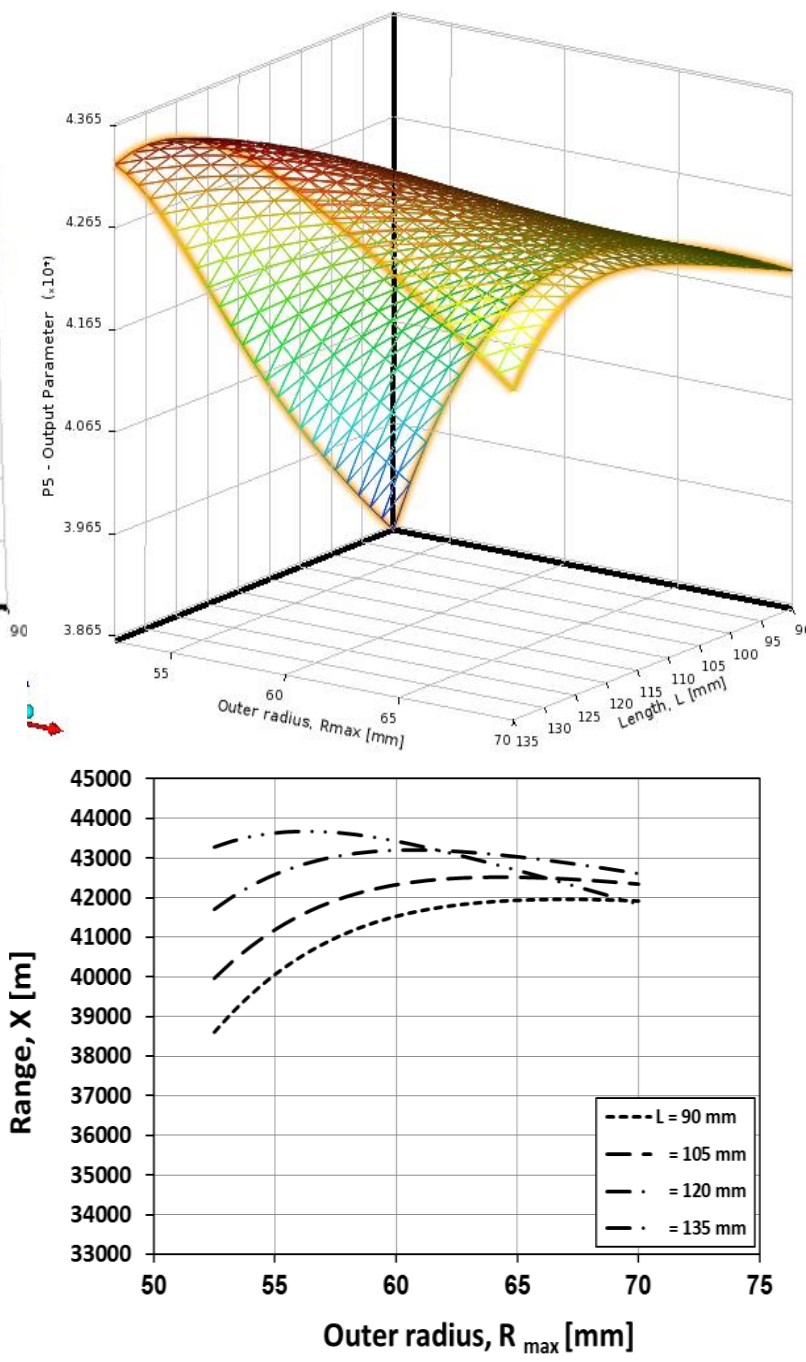

(b)

Fig. 7 The response surface of range change with grain $R_{\max }$ for different grain $L$ in the case PBB 4 when Ns $=2$ (a) and Ns $=4$ (b). 


\section{The cases of the multi-burn base bleed grain}

Table 7 shows the optimized design variables at each candidate point and the corresponding range $X_{o p}, X_{\text {anlt }}$ and the relative difference in range. For all cases it appears that the lower value of $R_{\text {in }}$ is preferred. Meanwhile, higher values of $D_{\text {exit }}$ are required for longer range to allow the high mass flow rate to flow with reasonable injection parameter. The maximum error was found in the case MBB3 where the number of design variables is the maximum. However the error level with respect to PBB $4 \mathrm{R}$ errors was satisfactory. Table 8 shows the comparison between the maximum values of $\mathrm{X}_{\text {anlt }}$ for each case for PBB and its corresponding value for MBB. As shown for all cases, the range increases when using multi-burn base bleed grain (MBB) compared with the corresponding range of original base bleed grain (PBB).

The percentage of range increase is maximum in case MBB4 when $\mathrm{N}_{\mathrm{s}}=2$ and equals to $15 \%$. With the increase of the number of slots, the gain in the range by applying the multi burn grain decreases as seen for all cases. This may be justified by that, two ways to re-configure the grain to increase the range (increase the $\mathrm{N}_{\mathrm{s}}$ and multi-burn base bleed grain) are applied in the same time leads to increase in the injection parameter more than required and a reduction in burn time and hence reduces the efficiency of base bleed.

Table 9 shows the effect of Ns for both configurations (PBB - MBB); it is clear that the range increase with the increase of number of slots for both cases. However the percentage is less in case of MBB because of the already achieved gain in range by the use of MBB.

Table 10 shows that the range increases for cases (2, 3 and 4) with respect to case \# 1 for both $\mathrm{PBB}$ and $\mathrm{MBB}$ in case of different Ns. With the incorporation of more design variables in the study, the percentage of range increase gets higher. The highest percentage occurs in case \#4 in which all the parameters of base bleed grain are included in optimization formulation. 
Table 7. Optimized design variables at each candidate point, the corresponding range $X_{\mathrm{op}}, \mathrm{X}_{\mathrm{anlt}}$ and the relative difference in range.

\begin{tabular}{|c|c|c|c|c|c|c|c|c|c|c|c|c|}
\hline \multirow{2}{*}{ No. } & \multirow{2}{*}{ Conf. } & \multirow{2}{*}{$\begin{array}{l}\text { No. of } \\
\text { slots, } \\
\mathrm{N}_{\mathrm{S}}\end{array}$} & \multicolumn{7}{|c|}{ Optimized Design Variable } & \multicolumn{2}{|c|}{$\begin{array}{c}\text { Predicted Range, } \mathrm{X} \\
{[\mathrm{m}]}\end{array}$} & \multirow{2}{*}{$\begin{array}{c}\text { Abs. } \\
\text { Relative } \\
\text { Differ. in } \\
\text { Range [\%] }\end{array}$} \\
\hline & & & $\begin{array}{c}\mathrm{R}_{\max }, \\
{[\mathrm{mm}} \\
]\end{array}$ & $\begin{array}{c}\mathrm{R}_{\mathrm{in}}, \\
{[\mathrm{mm}} \\
]\end{array}$ & $\begin{array}{c}\mathrm{L}, \\
{[\mathrm{mm}} \\
]\end{array}$ & $\begin{array}{c}\mathrm{D}_{\text {exit }}, \\
{[\mathrm{mm}} \\
]\end{array}$ & $\begin{array}{l}\mathrm{BR} 1, \\
{[\mathrm{~mm} / \mathrm{s}]}\end{array}$ & $\mathrm{L}_{\%}$ & $\begin{array}{c}\mathrm{BR} 2, \\
{[\mathrm{~mm} / \mathrm{s}} \\
]\end{array}$ & $\begin{array}{l}X_{o p}, \\
\text { [m] }\end{array}$ & $\begin{array}{l}X_{a n l t}, \\
{[\mathrm{~m}]}\end{array}$ & \\
\hline \multirow{9}{*}{1} & \multirow{9}{*}{$\begin{array}{c}\text { Case \# } \\
1, \\
\text { MBB1 }\end{array}$} & \multirow{3}{*}{2} & - & - & - & - & - & 0.34 & 2 & 41616 & 41586 & $0.1 \%$ \\
\hline & & & - & - & - & - & - & 0.35 & 1.94 & 41614 & 41571 & $0.1 \%$ \\
\hline & & & - & - & - & - & - & 0.337 & 2.13 & 41609 & 41606 & $0.01 \%$ \\
\hline & & \multirow{3}{*}{3} & - & - & - & - & - & 0.347 & 1.7 & 41888 & 41781 & $0.3 \%$ \\
\hline & & & - & - & - & - & - & 0.34 & 1.78 & 41872 & 41801 & $0.2 \%$ \\
\hline & & & - & - & - & - & - & 0.32 & 1.87 & 41857 & 41817 & $0.1 \%$ \\
\hline & & \multirow{3}{*}{4} & - & - & - & - & - & 0.346 & 1.7 & 41947 & 41908 & $0.09 \%$ \\
\hline & & & - & - & - & - & - & 0.315 & 1.78 & 41930 & 41914 & $0.04 \%$ \\
\hline & & & - & - & - & - & - & 0.103 & 2.44 & 41919 & 41881 & $0.09 \%$ \\
\hline \multirow{9}{*}{2} & \multirow{9}{*}{$\begin{array}{c}\text { Case \# } \\
2, \\
\text { MBB2 }\end{array}$} & \multirow{3}{*}{2} & - & - & - & - & 1.18 & 0.31 & 2.13 & 41638 & 41657 & $0.05 \%$ \\
\hline & & & - & - & - & - & 1.19 & 0.32 & 2.05 & 41635 & 41632 & $0.01 \%$ \\
\hline & & & - & - & - & - & 1.16 & 0.33 & 1.98 & 41629 & 41614 & $0.04 \%$ \\
\hline & & \multirow{3}{*}{3} & - & - & - & - & 1.17 & 0.34 & 1.70 & 41935 & 41813 & $0.29 \%$ \\
\hline & & & - & - & - & - & 1.18 & 0.31 & 1.82 & 41911 & 41845 & $0.16 \%$ \\
\hline & & & - & - & - & - & 1.14 & 0.31 & 1.92 & 41886 & 41857 & $0.07 \%$ \\
\hline & & \multirow{3}{*}{4} & - & - & - & - & 1.14 & 0.33 & 1.70 & 41997 & 41930 & $0.16 \%$ \\
\hline & & & - & - & - & - & 1.12 & 0.28 & 1.78 & 41973 & 41940 & $0.08 \%$ \\
\hline & & & - & - & - & - & 1.19 & 0.23 & 1.85 & 41964 & 41960 & $0.01 \%$ \\
\hline \multirow{9}{*}{3} & \multirow{9}{*}{$\begin{array}{c}\text { Case \# } \\
3, \\
\text { MBB3 }\end{array}$} & \multirow{3}{*}{2} & - & 19.8 & - & 46.6 & 1.17 & 0.50 & 2.13 & 41675 & 41433 & $0.580 \%$ \\
\hline & & & - & 18.5 & - & 55.6 & 1.17 & 0.35 & 2.16 & 41675 & 41687 & $0.029 \%$ \\
\hline & & & - & 19.0 & - & 45.6 & 1.18 & 0.45 & 2.18 & 41671 & 41580 & $0.219 \%$ \\
\hline & & \multirow{3}{*}{3} & - & 19.0 & - & 51.3 & 1.26 & 0.20 & 2.50 & 42066 & 42053 & $0.03 \%$ \\
\hline & & & - & 18.5 & - & 42.2 & 1.14 & 0.28 & 1.83 & 42034 & 41953 & $0.19 \%$ \\
\hline & & & - & 18.1 & - & 48.9 & 1.25 & 0.28 & 1.72 & 42033 & 41942 & $0.22 \%$ \\
\hline & & \multirow{3}{*}{4} & - & 18.0 & - & 54.3 & 1.07 & 0.50 & 1.70 & 42274 & 42041 & $0.55 \%$ \\
\hline & & & - & 18.2 & - & 43 & 1.16 & 0.24 & 1.75 & 42160 & 42154 & $0.02 \%$ \\
\hline & & & - & 18.4 & - & 48.5 & 1.12 & 0.49 & 1.70 & 42157 & 42051 & $0.25 \%$ \\
\hline \multirow{9}{*}{4} & \multirow{9}{*}{$\begin{array}{c}\text { Case \# } \\
4, \\
\text { MBB4 }\end{array}$} & \multirow{3}{*}{2} & 60.0 & 18.0 & 135 & 50.8 & 0.90 & 0.10 & 1.92 & 43847 & 41684 & $5.19 \%$ \\
\hline & & & 54.5 & 18.7 & 134 & 47.5 & 0.96 & 0.11 & 1.88 & 43534 & 41505 & $4.89 \%$ \\
\hline & & & 63.1 & 18.2 & 116 & 48.8 & 0.91 & 0.27 & 2.50 & 42633 & 42435 & $0.47 \%$ \\
\hline & & & 63.7 & 20.7 & 130 & 52.9 & 0.95 & 0.19 & 2.03 & 43433 & 42743 & $1.61 \%$ \\
\hline & & 3 & 64.7 & 18.0 & 116 & 52 & 0.90 & 0.10 & 2.28 & 43347 & 42485 & $2.03 \%$ \\
\hline & & & 63.5 & 18.8 & 107 & 55.5 & 1.00 & 0.22 & 2.38 & 42974 & 42721 & $0.59 \%$ \\
\hline & & & 66.1 & 18.0 & 120 & 50.5 & 0.90 & 0.10 & 1.85 & 43782 & 42941 & $1.96 \%$ \\
\hline & & 4 & 63.7 & 20.7 & 130 & 52.9 & 0.95 & 0.148 & 2.03 & 43706 & 43004 & $1.63 \%$ \\
\hline & & & 68.8 & 19.2 & 81.7 & 54.1 & 1.03 & 0.17 & 2.17 & 43695 & 42301 & $3.30 \%$ \\
\hline
\end{tabular}


Table 8. Effect of applying the multi-burn base bleed for the studied cases

\begin{tabular}{|c|c|c|c|c|c|}
\hline No. & $\begin{array}{c}\text { case } \\
\text { designation }\end{array}$ & $\begin{array}{l}\text { No. of } \\
\text { Slots, Ns }\end{array}$ & $\begin{array}{l}\text { Range of original } \\
\text { base bleed, X [m] }\end{array}$ & $\begin{array}{c}\text { Range of multi-burn } \\
\text { base bleed, } X[\mathrm{~m}]\end{array}$ & $\begin{array}{l}\Delta X \\
{[\%]}\end{array}$ \\
\hline \multirow{3}{*}{1} & \multirow{3}{*}{ Case \# 1} & $\mathrm{Ns}=2$ & 40516.2 & 41607 & $12 \%$ \\
\hline & & $\mathrm{Ns}=3$ & 41236.8 & 41818 & $6 \%$ \\
\hline & & $\mathrm{Ns}=4$ & 41717.5 & 41915 & $2 \%$ \\
\hline \multirow{3}{*}{2} & \multirow{3}{*}{ Case \# 2} & $\mathrm{Ns}=2$ & 40703 & 41657 & $10.4 \%$ \\
\hline & & $\mathrm{Ns}=3$ & 41440 & 41857 & $4.2 \%$ \\
\hline & & $\mathrm{Ns}=4$ & 41872 & 41960 & $0.9 \%$ \\
\hline \multirow{3}{*}{3} & \multirow{3}{*}{ Case \# 3} & $\mathrm{Ns}=2$ & 40728 & 41687 & $10.4 \%$ \\
\hline & & $\mathrm{Ns}=3$ & 41613 & 42053 & $4.4 \%$ \\
\hline & & $\mathrm{Ns}=4$ & 42131 & 42154 & $0.2 \%$ \\
\hline \multirow{3}{*}{4} & \multirow{3}{*}{ Case \# 4} & $\mathrm{Ns}=2$ & 41006 & 42435 & $15.0 \%$ \\
\hline & & $\mathrm{Ns}=3$ & 41905 & 42743 & $8.1 \%$ \\
\hline & & $\mathrm{Ns}=4$ & 42494 & 43004 & $4.6 \%$ \\
\hline
\end{tabular}

Table 9. Effect of number of slots for all studied cases

\begin{tabular}{|c|c|c|c|c|c|c|c|c|}
\hline \multirow{2}{*}{ No. } & \multirow{2}{*}{$\begin{array}{c}\text { case } \\
\text { designation }\end{array}$} & \multirow{2}{*}{$\begin{array}{l}\text { No. of } \\
\text { Slots, Ns }\end{array}$} & \multicolumn{3}{|c|}{$\begin{array}{l}\text { Range of original base } \\
\text { bleed, } X[\mathrm{~m}]\end{array}$} & \multicolumn{3}{|c|}{$\begin{array}{c}\text { Range of multi-burn base } \\
\text { bleed, X [m] }\end{array}$} \\
\hline & & & $\mathrm{Ns}=2$ & $\mathrm{Ns}=3$ & $\mathrm{Ns}=4$ & $\mathrm{Ns}=2$ & $\mathrm{Ns}=3$ & $\mathrm{Ns}=4$ \\
\hline \multirow{2}{*}{1} & \multirow{2}{*}{ Case \# 1} & Range & \multirow{2}{*}{40516} & 41236.8 & 41717.5 & \multirow{2}{*}{41607} & 41818 & 41915 \\
\hline & & $\Delta \mathrm{X}[\%]$ & & $8.0 \%$ & $13.3 \%$ & & $2.1 \%$ & $3.0 \%$ \\
\hline \multirow[b]{2}{*}{2} & \multirow{2}{*}{ Case \# 2} & Range & \multirow{2}{*}{40703} & 41440 & 41872 & \multirow{2}{*}{41657} & 41857 & 41960 \\
\hline & & $\Delta \mathrm{X}[\%]$ & & $8.0 \%$ & $12.7 \%$ & & $2.0 \%$ & $3.0 \%$ \\
\hline \multirow{2}{*}{3} & \multirow{2}{*}{ Case \# 3} & Range & \multirow{2}{*}{40728} & 41613 & 42131 & \multirow{2}{*}{41687} & 42053 & 42154 \\
\hline & & $\Delta \mathrm{X}[\%]$ & & $9.6 \%$ & $15.2 \%$ & & $3.6 \%$ & $4.6 \%$ \\
\hline \multirow{2}{*}{4} & \multirow{2}{*}{ Case \# 4} & Range & \multirow{2}{*}{41006} & 41905 & 42494 & \multirow{2}{*}{42435} & 42743 & 43004 \\
\hline & & $\Delta \mathrm{X}[\%]$ & & $9.5 \%$ & $15.7 \%$ & & $2.8 \%$ & $5.2 \%$ \\
\hline
\end{tabular}


Table 10. The effect of number of variables on range

\begin{tabular}{|c|c|c|c|c|c|c|c|}
\hline \multirow{3}{*}{ No. } & \multirow{3}{*}{$\begin{array}{c}\text { Case } \\
\text { designation }\end{array}$} & \multicolumn{6}{|c|}{ Range increase with respect to case $\# 1, \Delta \mathrm{X}[\%]$} \\
\hline & & \multicolumn{2}{|c|}{$\mathrm{Ns}=2$} & \multicolumn{2}{|c|}{$\mathrm{Ns}=3$} & \multicolumn{2}{|c|}{ Ns $=4$} \\
\hline & & PBB & $\mathrm{MBB}$ & PBB & $\mathrm{MBB}$ & PBB & $\mathrm{MBB}$ \\
\hline 1 & Case \# 2 & $2.1 \%$ & $0.5 \%$ & $2.1 \%$ & $0.4 \%$ & $1.5 \%$ & $0.4 \%$ \\
\hline 2 & Case \# 3 & $2.4 \%$ & $0.8 \%$ & $3.9 \%$ & $2.3 \%$ & $4.0 \%$ & $2.3 \%$ \\
\hline 3 & Case \# 4 & $5.4 \%$ & $8.2 \%$ & $6.9 \%$ & $9.0 \%$ & $7.6 \%$ & $10.5 \%$ \\
\hline
\end{tabular}

Figure 8 represents the predicted time change of injection parameter, for the case MBB 2 with different number of slots compared with the cases MBB 1, PBB 1 and PBB 2 when Ns $=2$. In all cases of MBB 2 injection parameter is higher than in case of the other cases in the first seconds and less in the remaining time. For all cases of MBB 1 and MBB 2, injection parameter takes the shape of 2 steps, the first one represents the burn time of the grain part with BR2, while the second one represents the burn time of the grain with BR1 which starts from the beginning. In general, injection parameter in case of MBB 1 and MBB 2 are much closer to optimum value when compared with the injection parameter of the original grain. Also, the application of multi-burn grain with the increase of Ns gets the pattern of injection more flatten leading to increase in range. For MBB 1 the burn time is longer than the case of MBB 2 as result of the lower BR1 (see table 7)

The benefit of base bleed on Mach number of the projectile when using multi-burn for Ns $=2$ is shown in Fig. 9. 


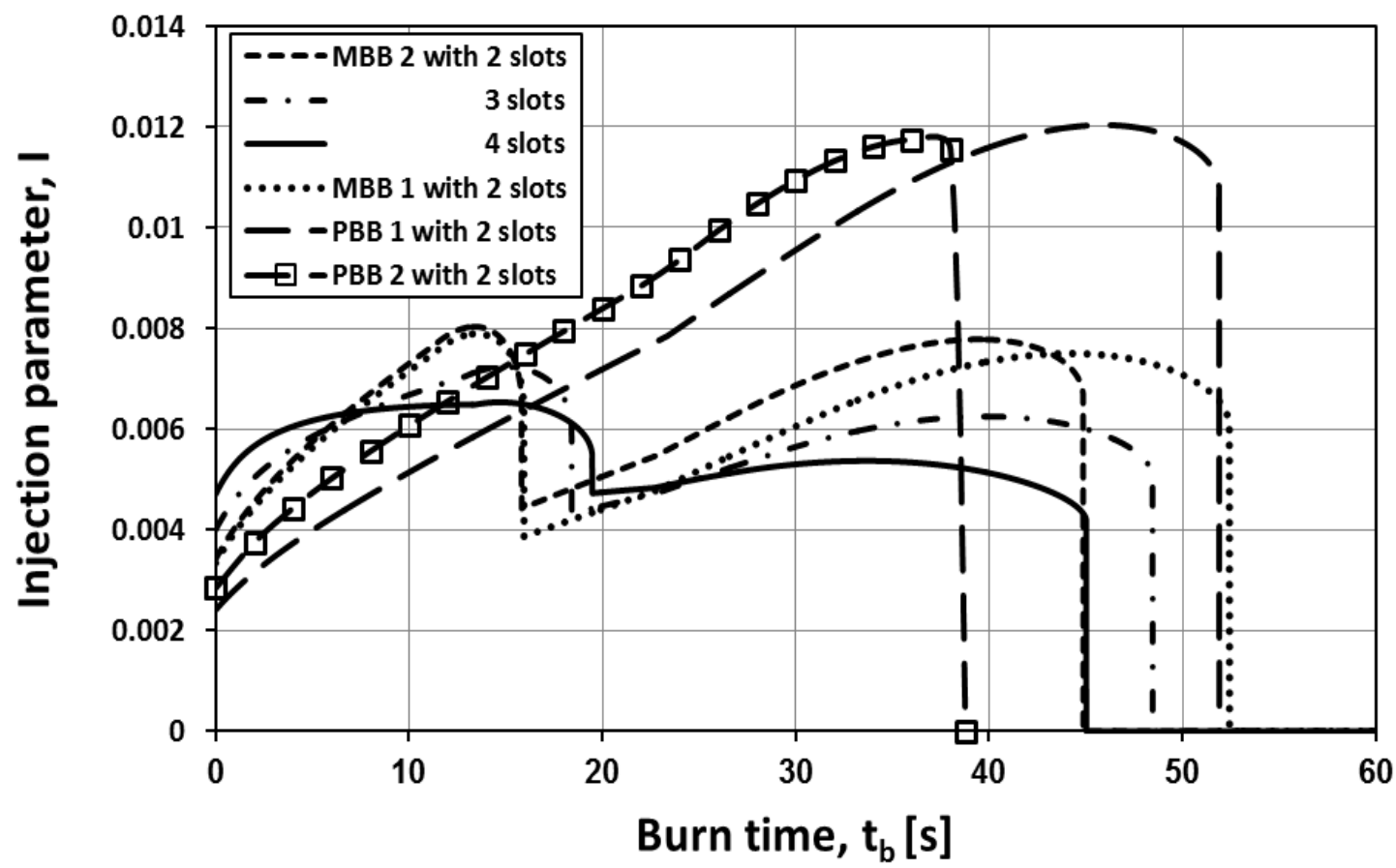

Fig. 8. Predicted time change of injection parameter, for the case MBB 2 with different number of slots compared with the cases MBB 1, PBB 1 and PBB 2 when Ns $=2$.

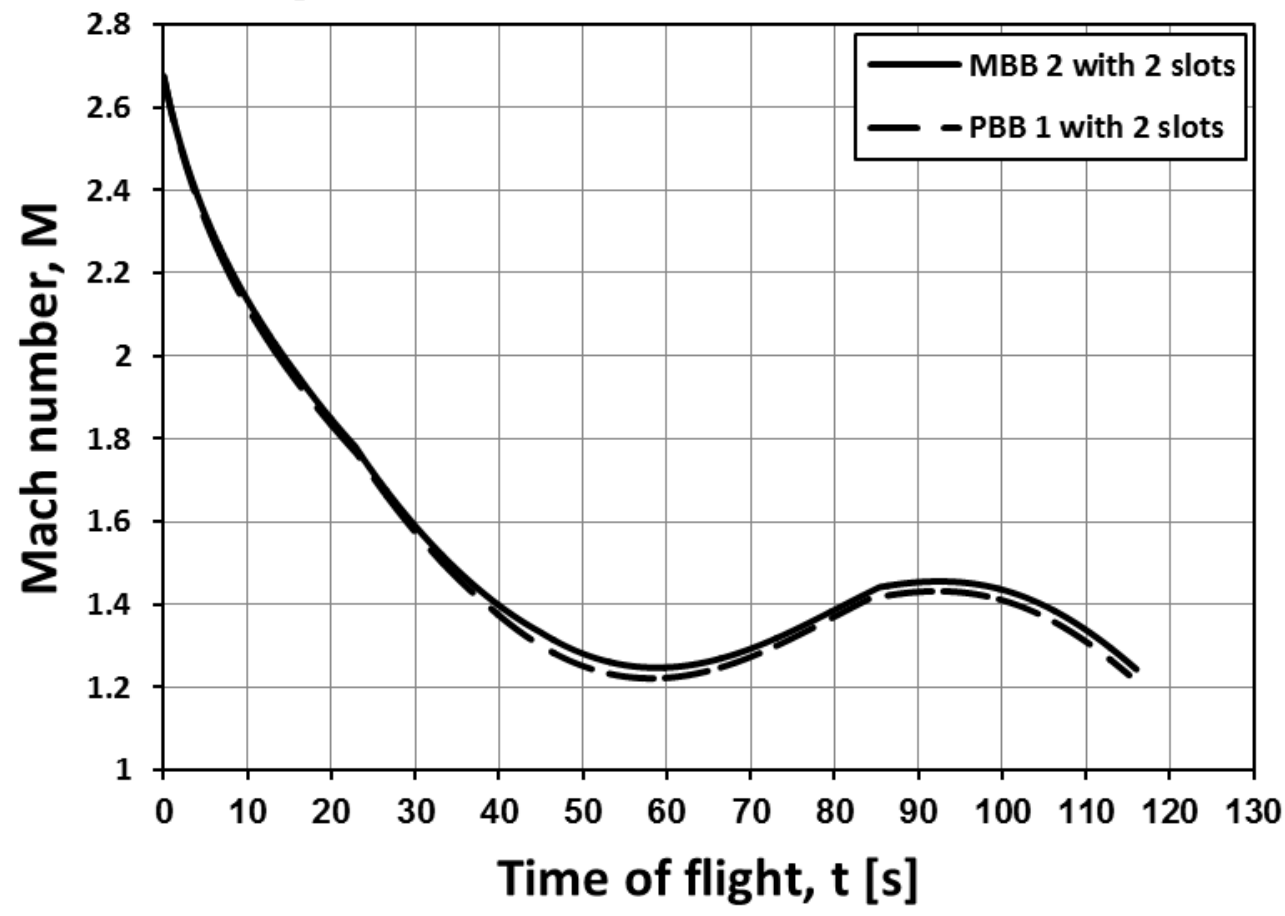

Fig. 9 Change of projectile Mach number versus time of flight at the first case of multiburn base bleed grain with 2 slots compared with the first case of the ordinary base bleed grain with 2 slots.

Figure 10 shows the response surface of range with $\mathrm{L} \%$ for different BR2 in case of Ns = 2 (a) and Ns $=4$ (b) for the case MBB 2. For both values of Ns and different values of BR2, range increases with the increase of $\mathrm{L} \%$ for all values of BR2 up to optimum value. More than 
this value the range decreases. The optimum value of $L \%$ increases with the decrease of BR2. For the same values of $\mathrm{L} \%$ and $\mathrm{BR} 2$ except for $\mathrm{BR} 2=2.5$ and $\mathrm{L} \%>0.4$, the range is higher in case of $\mathrm{Ns}=4$ when compared with the value in case of Ns $=2$. In case of Ns $=4$, it is more favorable the lower limits of BR2. This may related to the incorporation of increasing the number of slots.

Figure 11 shows the predicted time change of injection parameter for the fourth case of multiburn base bleed grain with different number of slots and compared with the original base bleed grain. In all cases of MBB 4, the injection parameter is higher than in case of the original base bleed grain for the first seconds and less for the remaining time. The benefit of that is as the same as mentioned in Fig.5. For all cases of MBB 4 injection parameter takes the shape of 2 steps. The first one represents the burn time of the grain part with BR2, while the second one represents the burn time of the grain part with BR1 which starts from the beginning. Also, burn time in all cases of MBB4 is longer than the time in case of original base bleed grain. This is related to higher $R_{\max }$ in the cases of MBB 4 and lower BR1 when compared with the corresponding values of the original grain.

The benefit of base bleed on Mach number of the projectile when using multi-burn for the case MBB 4 and Ns $=4$ is shown in Figure 12.

Figure 13 shows the surface response of the predicted change of range with the $\mathrm{R}_{\max }$ for different values of $\mathrm{L}$ in case of $\mathrm{MBB} 4$ for $\mathrm{Ns}=2$ and $\mathrm{Ns}=4$. For all values of $\mathrm{L}$, the range increases with the increase of $R_{\max }$ up to optimum value and after this value the range decreases. The optimum value of $R_{\max }$ decreases with the increase of $L$. For the same $R_{\max }$, the range increases with the increase of $\mathrm{L}$. The effect of outer radius change on range is higher than the effect of length change.

Figure 14 shows the predicted change of range with BR1 in the case MBB 3, $\mathrm{D}_{\text {exit }}=40 \mathrm{~mm}$ and $48 \mathrm{~mm}$ when $\mathrm{Ns}=2$ for the lower, medium and upper limits of both BR2 and L\%. It can be seen that the range for all cases increases with the increase of BR1 up to certain value and then it decreases. The value of BR1 that corresponds to maximum range decreases with the increase of the limits of BR2 and $L \%$ for the same $D_{\text {exit }}$. However it is higher in case of $D_{\text {exit }}=$ $48 \mathrm{~mm}$ for all Limits cases. The range is higher for all BR1 with the increase of the limits of both BR2 and L\% from low to medium but it decreases when the limits go to the upper limits. The justification of this could be as follows; in case of low limits, it requires higher value of BR1 to get optimum injection parameter. For the $D_{\text {exit }}=48 \mathrm{~mm}$, the accumulation of the pressure inside the base bleed chamber is less than in case of $D_{\text {exit }}=40 \mathrm{~mm}$ leading to reduction in mass flow rate [9] and consequently higher BR1 
is required to get near to optimum injection parameter. With the increase in the limits from low to medium, injection parameter get closer to the optimum value but when it reaches the upper limits, injection parameter exceeds optimum value leading to reduction in base bleed efficiency. Also, with the increase in the limits of both BR2 and L\% more mass flow rate is generated and larger $\mathrm{D}_{\text {exit }}$ is preferred [9].

\section{Conclusion}

- It's found that after optimization of all parameters the lower value of $\mathrm{R}_{\text {in }}$ is preferred. Meanwhile, higher values of $\mathrm{D}_{\text {exit }}$ are required for longer range to allow the high mass flow rate to stream with reasonable injection parameter.

- The optimum value of BR1 is variable depending on the grain configuration and number of slots. But the value decreases with the increase of $\mathrm{N}_{\mathrm{s}}$. Also it decreases with the increase of the studied variables as another source of mass flow generation such as $\mathrm{R}_{\max }, \mathrm{L}, \mathrm{BR} 2$ and $\mathrm{L} \%$ rate is effective besides BR1.

- The increase of number of slots increases the range for all studied cases of PBB, MBB. However the percentage of range increases is less for MBB when compared with the corresponding percentage of $\mathrm{PBB}$

- The application of multi-burn base bleed enhances the range regardless the number of slots and the studied cases when compared with the corresponding optimized original grain cases. The maximum increase of the range is found to be $15 \%$ in case MBB 4 with $\mathrm{N}_{\mathrm{s}}=2$.

- The increase of number of variables in the optimization process increases the calculated range reaching the maximum value in case if MBB 4 with $\mathrm{N}_{\mathrm{s}}=2$ and 4 . This reveals the benefit of optimization process.

- When applying MBB, for different values of BR2, the range increases with the increase of $\mathrm{L} \%$ up to its optimum value. More than this optimum value the range decreases. The optimum value of L\% increases with the decrease of BR2. For the same values of $L \%$ and $B R 2$, the range is higher in case of $N_{s}=4$ when compared with the value in case of $\mathrm{N}_{\mathrm{s}}=2$. In case of $\mathrm{N}_{\mathrm{s}}=4$, it is more favorable than lower limits of BR2.

- For all cases, the range increases with the increase of $R_{\max }$ up to optimum value and beyond this value the range decreases. The optimum value decreases with the increase of $L$. For the same $R_{\max }$, the range increases with the increase of $L$. The effect of outer radius change on range is higher than the effect of length change. 

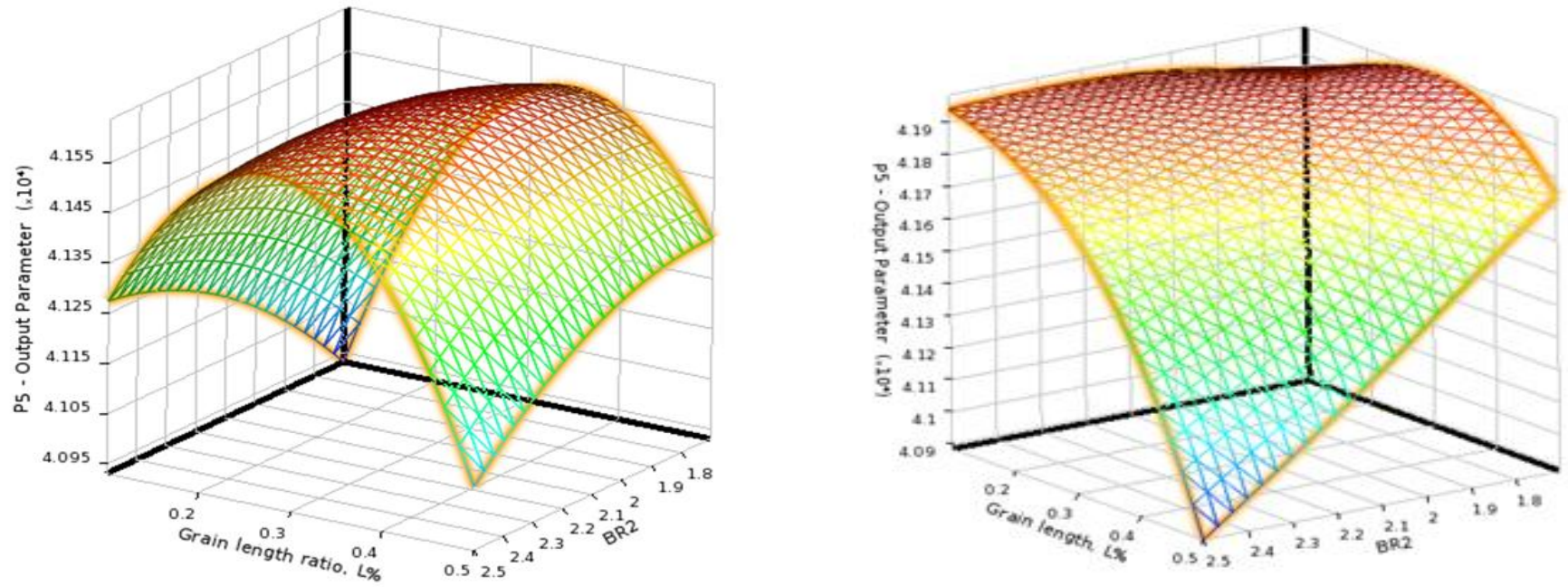

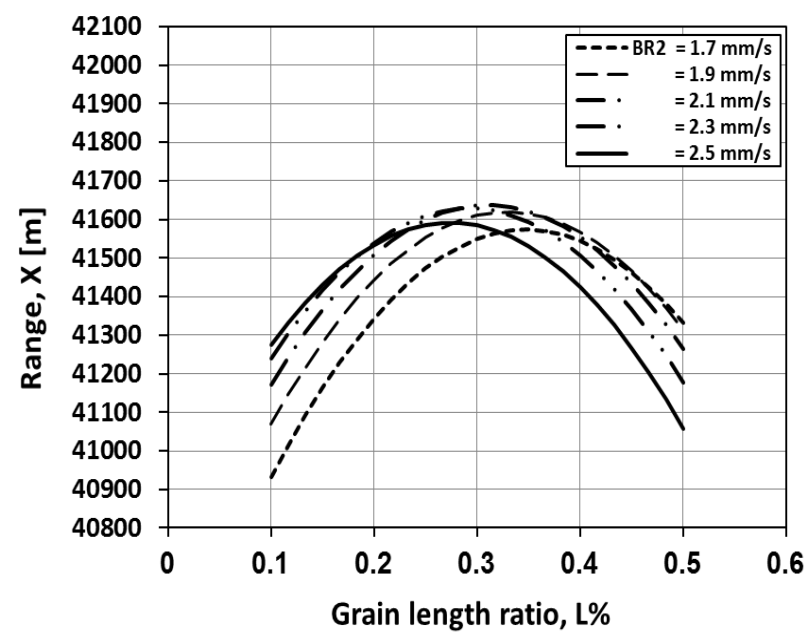

(a)

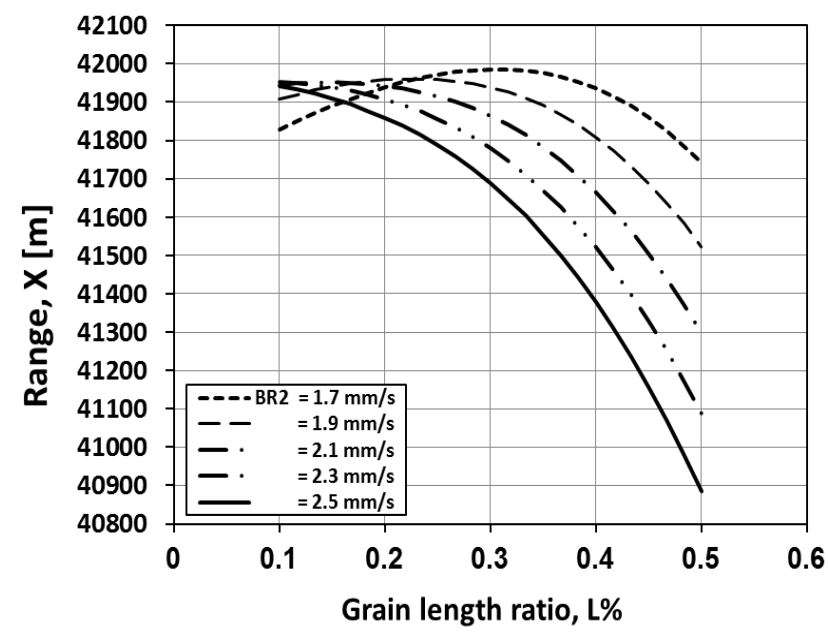

(b)

Fig. 10 The response surface of range with grain length ratio for different BR2 for the case MBB 2 when $\mathrm{Ns}=2$ (a) and $\mathrm{Ns}=4(\mathrm{~b})$

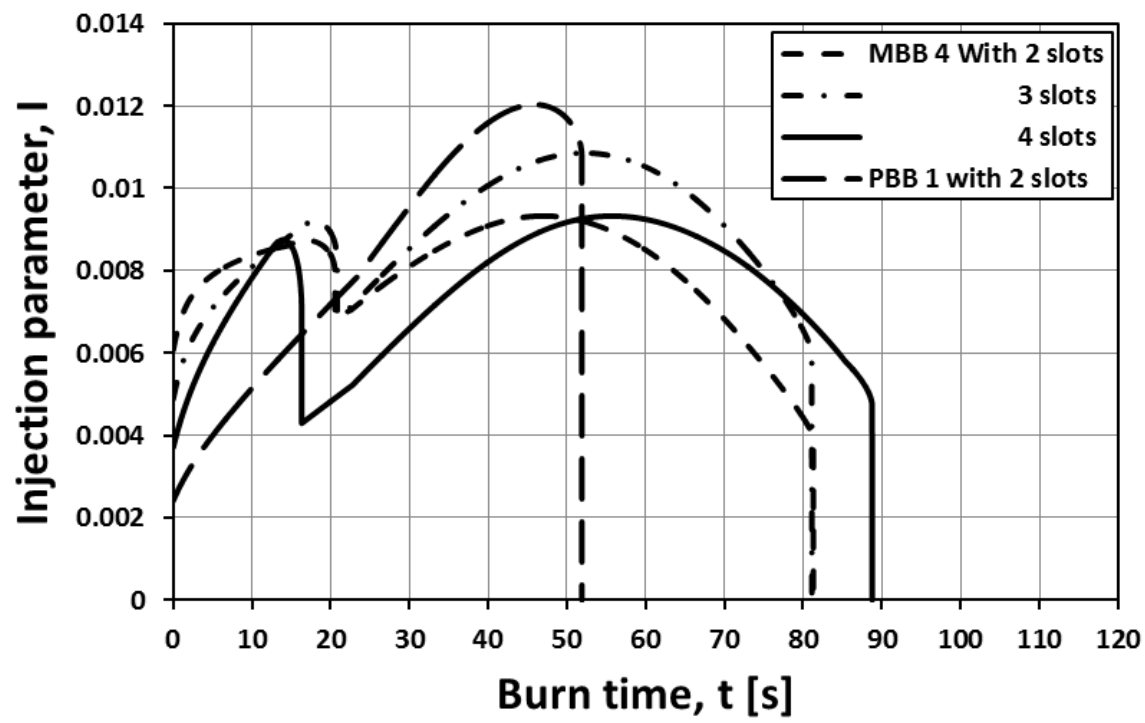

Fig. 11. Predicted time change of injection parameter, for the case MBB 4 with different number of slots compared with the case PBB 1 with Ns $=2$ 


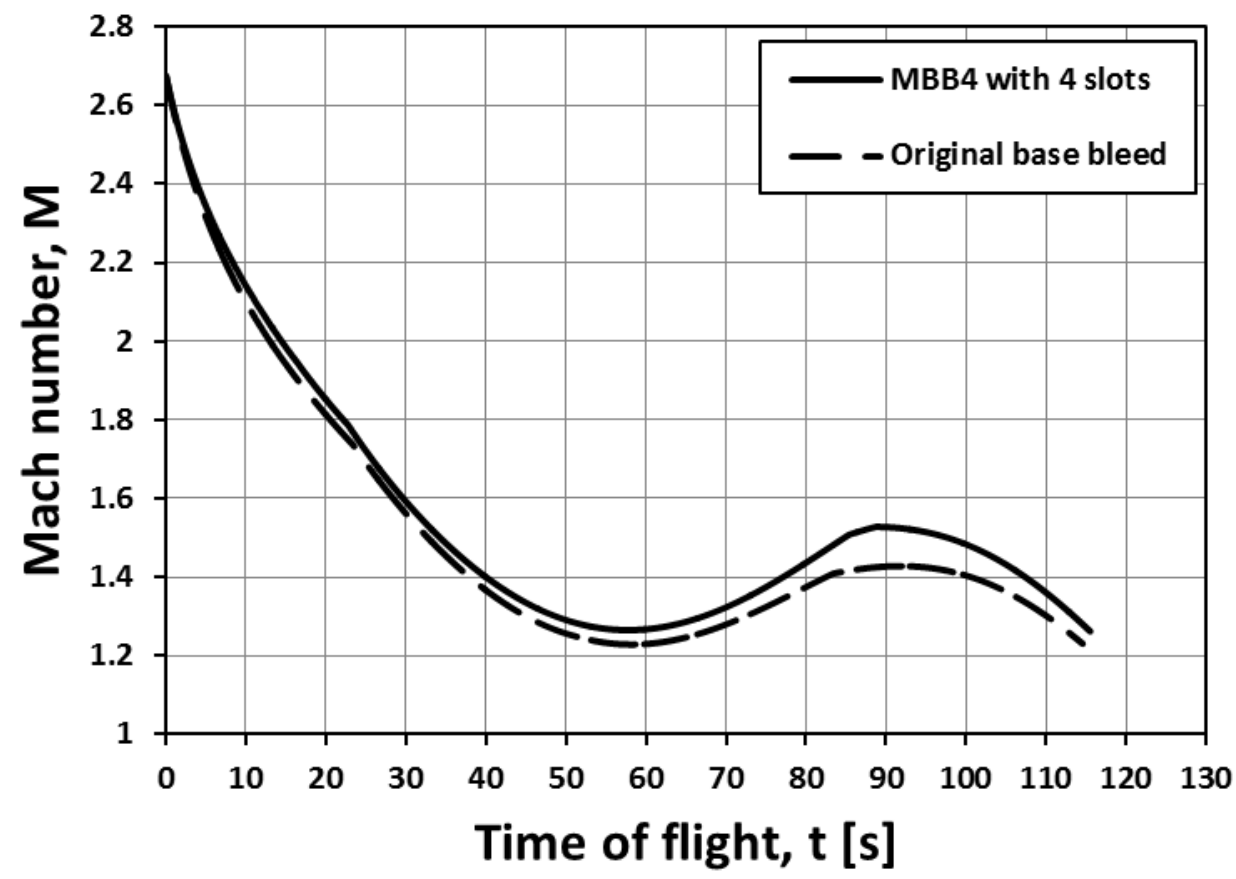

Fig. 12 Change of projectile Mach number versus time of flight at the fourth case of multi-burn base bleed grain with 4 slots compared with the original base bleed grain.
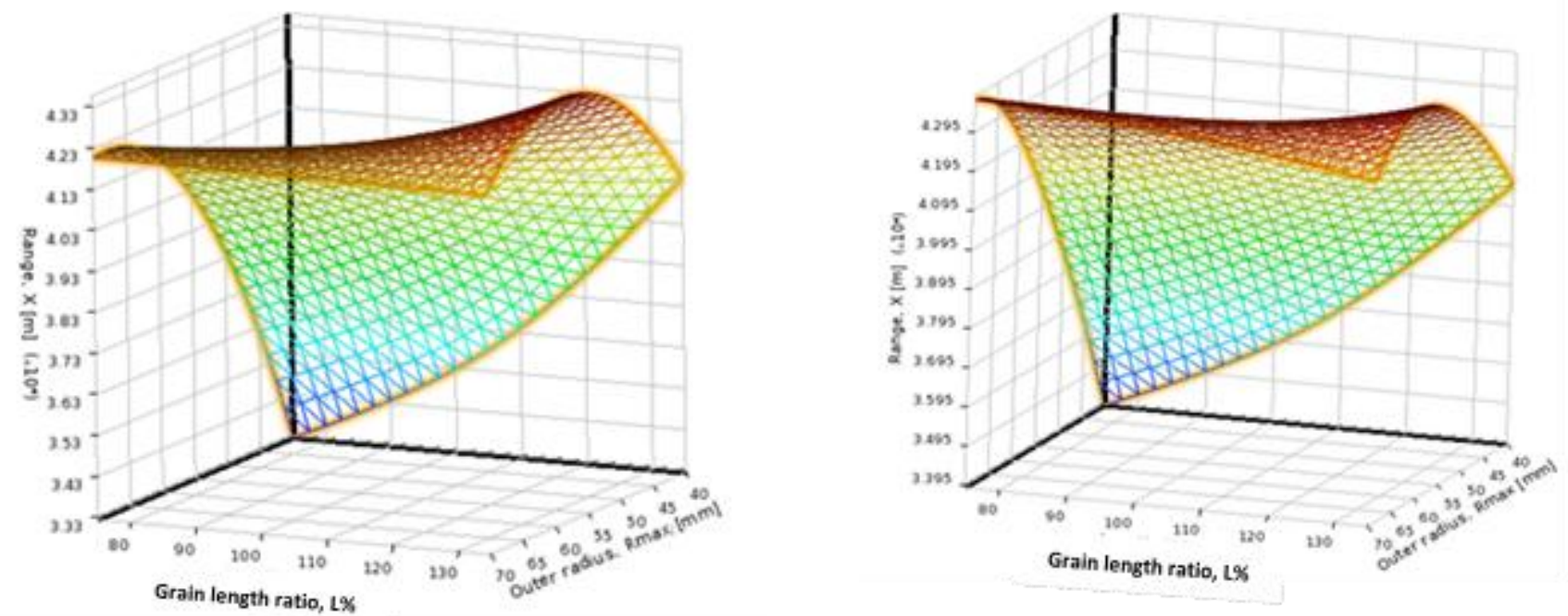

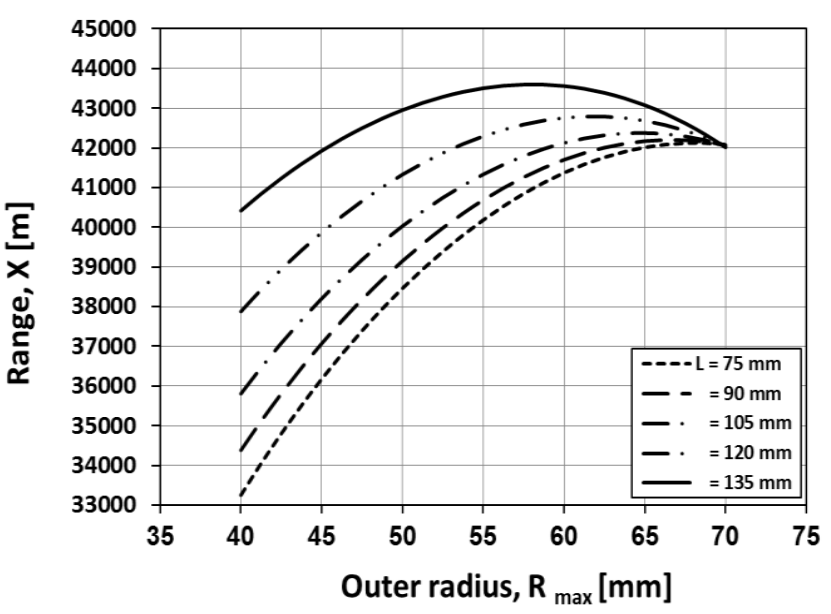

(a)

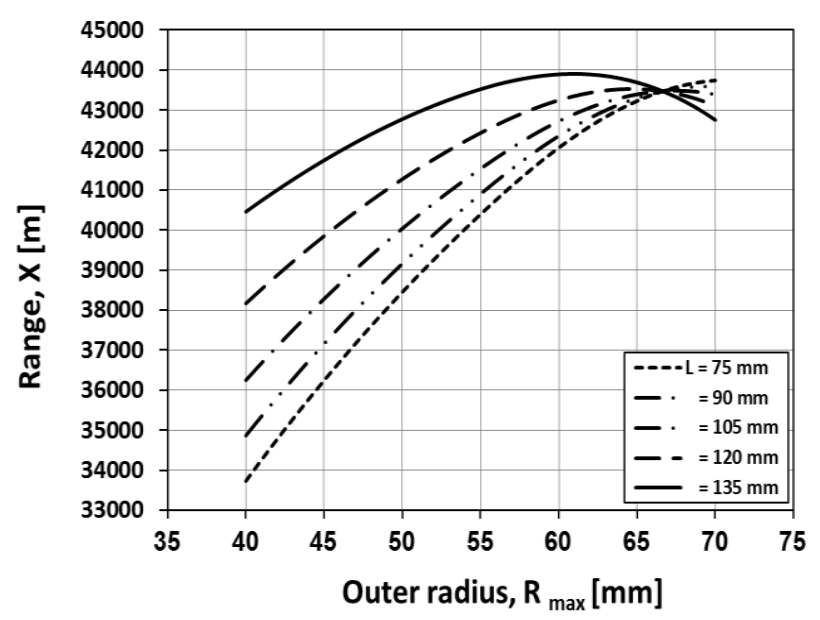

(b)

Fig. 13 The response surface of range with $R_{\max }$ for different $L$ in case of MBB4 for Ns $=2$ (a) and $\mathrm{Ns}=4(\mathrm{~b})$ 


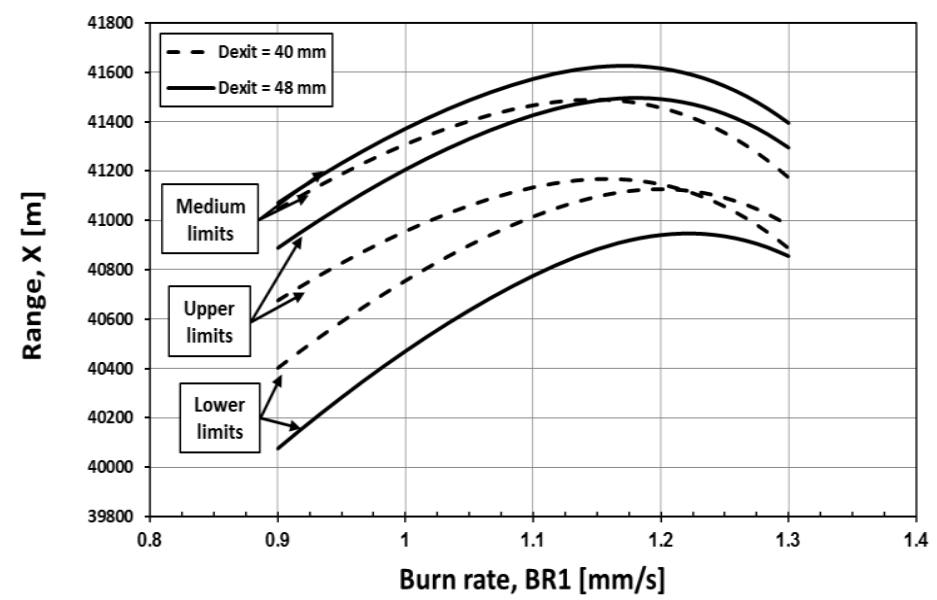

Fig. 14. The predicted change of range with BR1 in the case MBB 3, $\mathrm{D}_{\text {exit }}=40 \mathrm{~mm}$ and 48 $\mathrm{mm}$ when $\mathrm{Ns}=2$ for the lower, medium and upper limits of BR2 and L\%

\section{References}

[1] K. Anderson, N. E. Gunners and R. Hellgren, "Swedish Base Bleed - Increasing the Range of Artillery Projectiles through Base Flow", Propellants and Explosives I, 69-73 (1976).

[2] J. K. Fu and S. M. Liangt," Drag Reduction for Turbulent Flow over a Projectile: Part I, "Journal of Spacecraft and Rockets, Vol. 31, No. 1, pp. 85-92 (1994).

[3] T. Mathur and J. C. Button, "Base-Bleed Experiments with a Cylindrical Afterbody in Supersonic Flow", Journal of Spacecraft and Rockets, Vol. 33, No. 1, pp. 30-37 (1996).

[4] Y. K. Lee, H. D. Kim and S. Raghunathan, "Optimization of Mass Bleed for Base-Drag Reduction", AIAA Journal, Vol. 45, No. 7, pp. 1472-1477 (2007).

[5] H. Bournot, E. Daniel and R. Cayzac, "Improvements of the base bleed Effect Using Reactive Particles", International Journal of Thermal Sciences, Vol. 45, pp. 1052-1065 (2006).

[6] A. Davenas, "Solid Rocket Propulsion Technology", Pergamon Press Ltd., England, pp. 350 (1993).

[7] Slobodan jaramaz and milojko injac, "Effect of grain characteristics on range of artillary projectiles with base bleed", First International Symposium on Special Topics in Chemical Propulsion, Athens, Greece, 23-25 November (1988).

[8] H. A. Abou-Elela, A. Z. Ibrahim, O. K. Mahmoud and O. E. Abdel-Hamid, "Ballistic Analysis of a Projectile Provided with Base Bleed Unit", 15th International Confrence on Aerospace Scienses \& Aviation Technology,ASAT15, Egypt, 28 -30 May (2013).

[9] H. A. Abou-Elela, A. Z. Ibrahim, O. K. Mahmoud and O. E. Abdel-Hamid, "Effect of Base Bleed Dimensions on the Ballistic Performance of Artillery Projectile" $16^{\text {th }}$ International Confrence on Applied Mechanics and Mechanical Engineering, AMME-16, Egypt, 27-29 May (2014). 
[10] J. Danbergand, "Analysis of the Flight Performance of the $155 \mathrm{~mm}$ M864 Base Burn Projectile", Technical Report BRL-TR-3083, US Army Ballistic Research Laboratory (1990).

[11] K. Andersson, "Different Means to Reach Long Range > $65 \mathrm{Km}$, for Future 155mm Artillery Systems. Possibilities and Limitation", 17th Int. Sympo. on Ballistics, Midrand, South Africa, 23-27 March (1998).

[12] A.Z. Ibrahim, "Ballistic Performance of Base Bleed Unit", M. Sc. Thesis, MTC (2000).

[13] JMP, Design of Experiments, Release 6, SAS Institute Inc., Cary, NC, USA, 2005.

[14] Myers R. H., Montgomery D. C., "Response Surface Methodology - Process and Product Optimization Using Designed Experiments", Wiley Series in Probability and Statistics, New York, 1995.

[15] Nuran B., Yi C. "The Response Surface Methodology ", M.Sc. Thesis, University of South Bend, USA, 2007.

[16] Conn A.R., Scheinberg K., Vicente L.N., Introduction to Derivation-Free Optimization, Society for Industrial and Applied Mathematics and the Mathematical Programming Society, 2009.

[17] Kaymaz I., McMahon C. A.,"A Response Surface Method Based on Weighted Regression for Structural Reliability Analysis" Journal of Probabilistic Engineering Mechanics Vol. 20, pp. 11-17, 2005.

[18] Jasbir S. A., Introduction to Optimum Design, Elsevier Academic Press, second edition, 2004. 